\title{
Libros de la Universidad de Santo Tomás preservados en la Biblioteca Nacional
}

\section{Books from the University of Saint Thomas preserved in the National Library}

\author{
Ruth González-Arrieta* \\ Posgrado en Bibliotecología y Estudios de la Información, \\ Universidad de Costa Rica \\ Xinia Moya-López ${ }^{\star *}$ \\ Biblioteca Nacional Miguel Obregón Lizano, \\ Costa Rica
}

Recibido: 20 de mayo 2016 Aceptado: 04 de agosto 2016

Corregido: 24 de agosto 2016 Publicado: 30 de noviembre 2016

\begin{abstract}
Resumen
La Universidad de Santo Tomás fue la primera institución de Educación Superior costarricense, creada en 1843 por el Dr. José María Castro Madriz, por lo que se constituyó como universidad pionera del país. Inició labores universitarias en 1844, año en que ingresó para la Biblioteca, el primer embarque de libros provenientes de Europa. Con el transcurso del tiempo, la adquisición de textos afines a las materias de estudio como leyes, filosofía, literatura, gramática, teología e historia, entre otras, se acrecentó y, por ende, la colección bibliográfica aumentó. A pesar de la floreciente universidad, decisiones políticas incidieron en el cierre de la institución en 1888.

Con la clausura de la universidad, el educador Miguel Obregón Lizano impulsó que las colecciones de libros de la Biblioteca Universitaria se trasladaran a otra unidad de información, dando origen a la Biblioteca Nacional de Costa Rica, que ostenta su nombre y desde entonces resguarda los libros de la Universidad de Santo Tomás.
\end{abstract}

Palabras clave: Biblioteca Nacional, Biblioteca Universitaria, colecciones especiales, patrimonio, Historia.

\section{bibliotecas}




\begin{abstract}
The University of Saint Thomas was the first institution of Costa Rican Higher Education, created in 1843 by Dr. José María Castro Madriz, which was established as a pioneering university in the country. Starting academic work in 1844, when entered for the Library, the first shipment of books from Europe. Over time, the acquisition of related to the subjects of study such as law, philosophy, literature, grammar, theology and history, among others, books grew and therefore the bibliographic collection increased. Despite the flourishing university, political decisions influenced the closure of the institution in 1888.

With the closure of the university, educator Miguel Obregon Lizano urged that the book collections of the University Library was transferred to another unit of information, giving rise to the National Library of Costa Rica, which bears his name and since then protects the books University of Saint Thomas.
\end{abstract}

Keywords: National Library, University Library, Special Collections, Patrimony, History.

\title{
I. Introducción
}

Las universidades como instituciones de Educación Superior constituyen centros de pensamiento diverso en la enseñanza y el conocimiento en todas las ramas del saber humano y la investigación científica. Por consiguiente, las bibliotecas universitarias forman un eje colateral, ya que mediante los servicios y recursos bibliográficos, se apoya en los requerimientos de información; a la población usuaria conformada por estudiantes, profesores e investigadores.

La presente investigación refleja la colección de libros del acervo bibliográfico de la Universidad de Santo Tomás, primera institución universitaria de Costa Rica. Sin embargo, a escasos cuatro décadas de la apertura, Mauro Fernández quien fungía como Ministro de Instrucción Pública -en la actualidad se denomina Ministro de Educacióntomó la decisión de cerrar la universidad en 1888, dejando al país a la deriva sin ninguna institución de índole universitaria. Desde entonces, este hecho ha sido criticado por los intelectuales de la sociedad costa- 
rricense. Sin embargo, Fernández justificó su decisión aduciendo que el gobierno reformaría la universidad, pero primero debía de reorganizar la educación primaria y secundaria, bases de la educación superior.

Cuando se clausuró la Universidad de Santo Tomás, los recursos bibliográficos como los libros que eran compuestos generalmente por libros extranjeros, fueron trasladados por iniciativa de Miguel Obregón Lizano para la creación de la Biblioteca Nacional.

Entre los motivos de que la mayoría de libros provinieran del extranjero, destaca que el principal ente de la universidad denominada Dirección de Estudios, encargaba la adquisición de textos a comerciantes que viajaban a Europa, aunque desde el año de 1830 Miguel Carranza había creado en Costa Rica la primera imprenta $\mathrm{La} \mathrm{Paz}$ donde el Bachiller Rafael Francisco Osejo publicó el primer libro llamado Breves lecciones de Aritmética para el uso de los Alumnos de la Casa de Santo Tomás, institución educativa predecesora de la Universidad de Santo Tomás.

\section{Antecedentes}

En la época colonial Costa Rica dependía de España y durante ese periodo, en 1814, se creó la Casa de Enseñanza que se ubicó en San José, aunque la capital se situaba en Cartago. Una de las razones de ese hecho fue la influencia ilustrada y el crecimiento económico que experimentaba San José. Para esta época el mayor desarrollo de San José se debía al monopolio del tabaco y los negocios mercantiles facilitados por el aquel, por lo cual el Ayuntamiento de San José supervisaba el centro de estudios. Para ocupar el puesto de rector, se nombró al Bachiller Francisco Osejo, quien, entre sus funciones, se encargó de la cátedra de Filosofía, materia, que se impartía conjuntamente con Gramática, Sagrados Cánones y Teología Moral.

De acuerdo con González Villalobos (1989) a un año de fundada, intervino el Obispo García Pérez, quien estaba de visita en Costa Rica, y planteó una reorganización como la modificación del nombre por Casa de Enseñanza de Santo Tomás en la que el Rector se encargaría

\section{bibliotecas}


de la formación moral, política y religiosa; se nombraba un Vicerrector para coordinar lo relativo a planes de estudio y para otros fines, la supervisaba la Universidad de León.

Con el paso de los años, cuando Costa Rica se había independizado en 1821 de España, la Casa de Enseñanza de Santo Tomás tuvo diversas reorganizaciones de índole académica, jerárquica y administrativa.

\section{a. Universidad de Santo Tomás}

Transcurría la década del cuarenta del siglo XIX y reinaba la desestabilización en los estados circundantes, pues formaban parte de la federación, que era la República; factor que incidió entre nuestros gobernantes, quienes se preocuparon por los jóvenes que no pudieran continuar sus estudios superiores en el área, razón por la que optaron por brindar esa oportunidad en Costa Rica. Fue así como durante la administración de José María Alfaro y siendo Ministro General el Dr. José María Castro Madriz, hombre culto, liberal y visionario, con un doctorado en Derecho Civil y Maestro de Artes, se dispuso e influyó para crear una institución de educación superior. Al respecto, señala González-Villalobos (1989)

el 3 de mayo de 1843, firmaron ambos políticos el decreto mediante el cual se convirtió en Universidad la Casa de Enseñanza de Santo Tomás, destinándose para tales efectos el edificio de la enunciada Casa de Estudios, así como sus rentas, más otras nuevas consistentes en la tercera parte de las tercenas de tabaco del Estado. (p. 47)

Con la apertura de la universidad se enarbolaba una nueva era educativa para Costa Rica, como lo expresa González-García (2006, p. 151) "Cuando, en 1844, el Dr. José María Castro Madriz inaugura la Universidad de Santo Tomás, lo hace con una perspectiva muy clara sobre la función que la enseñanza debe cumplir en la sociedad".

En alusión a la inauguración de la Universidad de Santo Tomás, Láscaris, 1964 citado por Pérez (2012) acota "el 22 de abril de 1844, se 
inaugura la Universidad con el siguiente cuadro de estudios: Filosofía, Br. Nicolás Gallegos; Gramática, Br. Vicente Herrera; Jurisprudencia, Dr. José María Castro; Teología, Br. Francisco Calvo”. (p.194)

Pérez (2012) señala que los Estatutos de 1843 establecían una estructura jerárquica para dirigir la universidad, cuyos integrantes se nombraban anualmente para integrar una junta que operaba como ente autónomo del Estado, en cuya cúpula estaba la Dirección de Estudios, conformada por el rector y cuatro directores; fungiendo el Dr. José María Castro Madriz como primer rector; cada director tenía sus propias responsabilidades, con el fin de velar por la biblioteca, la docencia, la tesorería y la secretaría, aunque como miembros de la dirección, coordinaban funciones entre sí.

\section{b. Biblioteca Universitaria}

Como toda biblioteca universitaria, cuyo eje transversal es coadyuvar en los quehaceres académicos de una comunidad universitaria, en la Universidad de Santo Tomás el primer director, José María Zeledón, miembro de la Dirección de Estudios, se encargaba de administrar la biblioteca y en forma grupal la dirección autorizaba la adquisición de libros.

Además, en los estatutos de la Universidad de Santo Tomás de 1843, se estipulaba que cada cátedra asignara los libros de textos. En correlación a esta norma, explica Pérez (2012) que para la cátedra de lengua castellana y latina optaban por los libros de Salvá y Nebrija; en Matemática y Geografía, los textos de Aritmética de Bezont, La Geometría de La-Croix y la Geografía de Antillón y para la cátedra de Teología seleccionaban la Doctrina Cristiana de Ponget o Jlenry y Teología Moral del Padre Larraga u otro autor.

Así, en 1844 la dirección encargó al alemán Edward Wallerstein, quien exportaba café a Europa, adquirir libros para la Biblioteca Universitaria; el hecho fructificó en diciembre de 1844 como lo manifiesta: "El catálogo de las obras compradas, se publicó en febrero de 1845, en el Mentor Costarricense" (p.78).

\section{bibliotecas}


Aunado a lo descrito, Molina-Jiménez (1995) recalca la compra de otras obras, que correspondían a: Derecho, Filosofía, Historia, Otras Lenguas, Ciencia, Política, Literatura, Castellano, Economía, Religión y otras fuentes de información y a su vez transcribe algunas peculiaridades

pocos títulos, un peso ya significativo de las obras en francés, decenas de ejemplares de ciertos textos y varias colecciones compuestas por más de diez tomos; en las últimas, destaca el Dictionnariae de la conversation, en 52 volúmenes. El conjunto de libros adquirido, en esencia profano, prescindía casi de los escritos devotos, en contraste, el grueso de la compra se concentraba en los trabajos de leyes. (p. 80)

No obstante, a pesar de los propósitos de la Dirección de Estudios de brindar oportunidades a los jóvenes costarricenses, la Universidad de Santo Tomás tuvo diversos problemas. González-Villalobos (1989) expresa que había falta de profesores calificados y los estudiantes ingresaban con una escaza formación académica que afectaba el rendimiento de sus estudios. Por ende, para contrarrestar los problemas, la dirección solicitó en 1845 la intervención del Estado, para mejorar la formación preuniversitaria. Fue así como se ordenó crear instituciones secundarias como la Escuela Normal para hombres en 1846 y el Liceo de niñas para las mujeres en 1849 , cuyos graduados, se esperaba tuvieran alguna incidencia en la preparación de la niñez en lo que a educación de primaria se refiere.

Además, por presión de la Universidad ante el Congreso para que se diera un vínculo entre todo el sistema educativo, se decretó una reforma en los estatutos universitarios, así como la promulgación del Reglamento orgánico de instrucción pública el 14 de octubre de 1849. Esta reforma legal sustituía la Dirección de Estudios que antes era potestad de la Universidad por un Consejo de Instrucción Pública, cuyos integrantes eran nombrados por el Poder Ejecutivo, lo cual le restó autonomía al ente universitario.

Entre las funciones de este Consejo estaba la de asignar los libros de texto para la universidad y la primaria elemental; inclusive en el Regla- 
mento, capítulo 5 de los artículos 29 a 36 se transcriben las primeras normas que se estipulaban para la biblioteca y el aumento de funciones para el bibliotecario:

Art. 29. Habrá una biblioteca compuesta de los libros que actualmente existen y de los que en adelante adquiera la Universidad.

Art. 30. El bibliotecario será elegido por el Consejo de instrucción pública y se recibirá de la biblioteca un prolijo inventario.

Art. 31. La biblioteca estará abierta diariamente, tres horas por la mañana y dos por la tarde.

Art. 32. Podrán concurrir a ella todos los que quieran visitarla; mas solo podrán sacar libros, con permiso del Rector, y previo un recibo firmado, los individuos de la Universidad.

Art. 33. El que perdiere un libro deberá reponerle dentro del término que le señale el Rector, y si no le repusiere pagará el duplo del valor de la obra a que perteneciere y no podrá en lo sucesivo usar de la biblioteca.

Art. 34. El bibliotecario se dedicará a la conservación de los libros, manteniéndolos limpios y aseados, arreglados por orden de materias y colocados de una manera vistosa.

Art. 35. El Consejo de instrucción podrá ordenar la venta de aquellos libros duplicados; mas su importe se invertirá en la compra de aquellos que falten a la biblioteca y señaladamente de los que se necesiten como texto para enseñar en las cátedras que deben establecerse.

Art. 36. Todos los que recibieron grados de la Universidad, empleos, cátedras o alguna gracia, obsequiarán una obra cualquiera a la biblioteca (Pérez, 2012, p. 200).

En 1850, similar con la gestión del alemán transportista y comerciante, la Universidad coordinó con Vicente Aguilar, otro comerciante, para que viajara a Europa con Nazario Toledo, profesor de filosofía, con el fin de comprar libros para la biblioteca. Como lo describe Molina-Jiménez (1995)

\section{bibliotecas}


El paquete de obras comprado por Aguilar y Toledo se componía de 71 títulos en 1278 volúmenes...el énfasis temático sí varió, el libro piadoso se descartó, se abrió un espacio para los textos prácticos y se amplió la bibliografía para las áreas de Literatura, Ciencias e Historia. (p.81)

A la altura de 1853, la Universidad manifestaba una serie de contrariedades políticas y financieras, situación que coincidió con la firma del Concordato con el Papa Pio IX, el que, entre otras cosas, incluyó la declaración de la Universidad como Pontificia (Mora-Parra, 2015). Por ello, se cambiaba la estructura de la institución, delegando en el Obispo Anselmo Llorente el nombramiento de los profesores de los cursos religiosos y teología; así como vigilar que otras cátedras enseñaran conforme los principios cristianos. Sin embargo, por influencia de los liberales, estas resoluciones no prosperaron.

Molina-Jiménez (1995) alude al inventario de 1855 realizado por Vicente Herrera que comprendía 188 títulos, 2802 volúmenes; además en menos de un lustro, en 1859 el inventario registraba 139 volúmenes más que el anterior y casi la mitad de los volúmenes eran en idioma francés, ya que desde 1846 la Universidad de Santo Tomás impartía la cátedra de francés, por lo cual no prescindían de traducciones e inclusive la biblioteca estaba abierta al público.

No obstante, las dificultades de diversa índole de la Universidad de Santo Tomás, destaca Pérez (2012) en 1857 se crearon la Escuela de Farmacia y la Escuela de Medicina, esenciales para la salud de Costa Rica, ya que para esa época solo habían " 24 médicos y 8 boticas" o farmacias como se denominan en la actualidad.

En concordancia con lo anterior, Molina-Jiménez (1995) explica que la Biblioteca se benefició con la donación de libros del Dr. Karl Hoffmann que abarcaba una colección de 92 títulos en 148 volúmenes, la mayoría de medicina y ciencias naturales. Asimismo, en 1858 hubo reformas en los Estatutos de la universidad y se destinó un apartado para la biblioteca; como lo transcribe Pérez (2012) "el Bibliotecario siempre 
tendrá en regla el índice de todas las obras contenidas en la Biblioteca, para que fácilmente pueda ser registrada la que se busque, a cuyo efecto observará en su colocación el orden más fácil y cómodo" (p.211). Vinculado a las normas estatutarias para la Biblioteca Universitaria, el ciudadano costarricense Manuel Arguello, en 1859, emitió una misiva al Ministro de Instrucción Pública, ofreciendo ejercer el puesto de bibliotecario, lo cual le fue aceptado.

En alusión a Manuel Arguello Mora, primer bibliotecario de la biblioteca de la Universidad de Santo Tomás, Pérez (2012) relata

Estudió en la Universidad de Santo Tomás y en la Universidad de San Carlos en Guatemala. Es además sobrino del Presidente del país. A la edad de veinte años se interesa por abrir la Biblioteca nuevamente, y según está registrado, acepta el puesto de Bibliotecario ad honorem. (p. 214)

No obstante, la dedicación como bibliotecario de Manuel Arguello, en setiembre de 1859 su tío el Presidente Juan Rafael Mora Porras sufrió un Golpe de Estado, por lo cual ambos abandonaron el país y en consecuencia, la Universidad se quedó sin bibliotecario y se cerró la biblioteca, cuyo resultado fue el deterioro y pérdida de libros.

En 1860 de nuevo el Dr. José María Castro Madriz asume como rector de la Universidad de Santo Tomás y se restablecen los Estatutos de 1843 con la instauración de la Dirección de Estudios. Como medida para reabrir la Biblioteca Universitaria, se nombra al catedrático Francisco Gallardo con recargo de funciones, quien durante su gestión efectuó el inventario, mencionado anteriormente.

Durante el periodo que prosiguió varias personas ejercieron como bibliotecarias, pero sin la formación pertinente. No obstante, la Universidad continuaba en sus funciones académicas. Como parte de ello los abogados Ricardo Jiménez y Pérez Zeledón elaboraron en 1884 una selección de 250 títulos de libros con énfasis en Derecho, Historia, Filosofía, Política, Economía y Literatura.

\section{bibliotecas}


A su vez el país experimentaba un auge en la creación de instituciones educativas: el Colegio San Luis Gonzaga fundado en 1869 como primera institución de segunda enseñanza del país; el Liceo de Costa Rica, en 1887; el Instituto de Alajuela, en 1887; el Colegio de Señoritas en 1888 y el Colegio Seminario en 1894.

Paralelamente, se abrían espacios de lectura. Al respecto Pérez (2012) manifiesta que el " 4 de julio de 1879 se funda la Biblioteca de San Ramón, por iniciativa del Lic. Julián Volio Llorente" (p.232); además, “en ese mismo año...el doctor Valeriano Fernández Férraz (1831-1925) establece una Academia de Lectura en la capital" (p.236) y "Miguel Obregón, con 19 años de edad, junto con otros jóvenes y vecinos de la ciudad organiza el 11 de julio de 1880, en Alajuela la Sociedad de la Biblioteca" (p. 237).

A su vez, además de la imprenta La Paz fundada en 1830 se abrieron otros talleres de impresores como el de los Sibaja en Alajuela. En alusión a ello, expone Molina-Jiménez (2002) "La publicación de obras... se elevó de 51 títulos en la década de 1850, a 71 en la de 1860, a 97 en la de 1870 , a 169 en la de 1880 y a 303 en la de $1890 \ldots$ de los cuales el 25 por ciento procedía de talleres privados y el 75 por ciento de la Imprenta Nacional" (p.36), con relación a esta, publicaba lo concerniente al Estado costarricense.

Si bien la Universidad continuaba su curso, expresa Molina-Jiménez (1995)

El último episodio en las vicisitudes de las obras de Santo Tomás data de 1888, cuando el Gobierno de Bernardo Soto clausuró tal institución; en esa fecha, la colección se componía de unos 1585 títulos en aproximadamente 3.653 volúmenes. (p. 97)

\section{c. Biblioteca Nacional de Costa Rica}

Como corolario de la clausura de la Universidad de Santo Tomás, la Biblioteca Universitaria quedaba a la deriva; no obstante, manifiesta Solano-Navarro (2014) "mediante acuerdo número 231 del 13 de octubre 
de 1888 por iniciativa de Miguel Obregón Lizano, bajo la presidencia de don Bernardo Soto" (p. 15) fructificaron las gestiones ante las autoridades competentes, para que los libros de la Biblioteca Universitaria se refundieran con el material documental del Archivo de Rezagos creado en 1882 y la Oficina de Depósito y Canje de Publicaciones fundada en 1887 y así conformar el acervo de la Biblioteca Nacional de Costa Rica.

Con respecto a los recursos bibliográficos que originaron la Biblioteca Nacional, Zeledón, 1969, citado por la autora (2014) “inició su funcionamiento con cerca 4.000 volúmenes entre libros, periódicos, revistas, audiovisuales, obras de referencia, folletos, fotografías y mapas publicados en Costa Rica y en el extranjero" (p.15). Asimismo, Solano y Zamora (2010) expresan: "Su bibliotecario fue don Bernardo Quirós. El 16 de octubre de 1961 por Decreto $N^{\text {o. }} 18$ fue bautizada con el nombre del educador Miguel Obregón Lizano" (p. 26) como un reconocimiento a su loable labor en las bibliotecas costarricenses.

Aunado a lo anterior, Moya-López (2015, p.37) explica que la Biblioteca Nacional Miguel Obregón Lizano es depositaria del Patrimonio Bibliográfico Nacional, ya que mediante la Ley de Derecho de Autor y Derechos Conexos, artículo $\mathrm{N}^{\text {o }} 106$ se "establece la obligatoriedad que tiene toda persona jurídica o pública de entregar un ejemplar de toda producción impresa o en cualquier otro soporte a la Biblioteca Nacional... y la Ley de Imprenta, artículo $\mathrm{N}^{\text {o. }} 6$ estipula la obligatoriedad que tiene todo editor de entregar a la Biblioteca Nacional dos ejemplares de toda obra que publique" por lo cual han coadyuvado a enriquecer las colecciones de la institución.

La estructura de la Biblioteca Nacional establece varias unidades para brindar los servicios a los usuarios como el Departamento de Investigación y Bibliografía, el Departamento de Referencia y el Departamento de Circulación y Préstamo que velan por los diferentes tipos de colecciones.

Como parte de las directrices de la Biblioteca Nacional, para la conservación del acervo bibliográfico, se creó la Sala de Colecciones Especiales Adolfo Blen, al respecto expresa Solano-Navarro (2014)

\section{bibliotecas}


la Sala de Colecciones Especiales Adolfo Blen se inauguró con cerca de 35.000 documentos pertenecientes a las colecciones de libros extranjeros publicados durante los siglos XVII, XVIII, XIX, la colección de libros extranjeros denominada Colección de Santo Tomás, donada a la Biblioteca Nacional al cierre de la Universidad de Santo Tomás en 1888. (p. 36)

Aunado a la Sala, Moya-López (2015) menciona diversos tipos de fuentes de información y algunas características

libros nacionales y extranjeros, revistas nacionales, obras de referencia...con características especiales, por su fecha de publicación, formato, características topográficas y al carácter que ostentaban como ediciones publicadas en Costa Rica, de carácter único en la Biblioteca y en algunos casos en el país. (p. 52)

\section{Metodología}

La investigación bibliográfica se realizó entre los años 2014 y 2015 y comprendió el análisis de publicaciones sobre la Universidad de Santo Tomás para determinar el desarrollo histórico de la primera institución de Educación Superior de Costa Rica; al mismo tiempo, se estudiaron fuentes de información de la historia y origen de la Biblioteca Nacional Miguel Obregón Lizano como artículos de libros, revistas, periódicos y tesis.

Asimismo, en la Sala de Colecciones Especiales Adolfo Blen de la Biblioteca Nacional, se investigaron los libros extranjeros que conserva la Colección de Santo Tomás, por ende, se utilizaron guantes de látex, para evitar un daño por la fragilidad y antigüedad de los libros. Se determinó que la mayoría de los libros de la Colección de Santo Tomás están en buen estado, solamente, se identificaron tres con problemas de comején, uno con serios problemas y a otro le falta la portada.

Derivados del estudio, se identificaron los libros extranjeros de la Colección de Santo Tomás, compilados por la investigadora Moya-López (2015) quien determinó que comprenden 1335 documentos en cuatro idiomas: 673 en español, 643 en francés, 17 en inglés, 1 en italiano y 1 en latín. 
Para recopilar los elementos básicos de la descripción bibliográfica, se llevó a cabo la transcripción del texto original, como lo reflejan los Cuadros 1 y 2.

\section{Cuadro 1}

\section{Libros de la Universidad de Santo Tomás conservados en la Biblioteca Nacional}

\begin{tabular}{|c|c|c|}
\hline AUTOR & TÎTULO & $\begin{array}{l}\text { AÑO DE } \\
\text { PUBLICACIÓN }\end{array}$ \\
\hline A. Bouchardat & $\begin{array}{l}\text { Annuaire Thérapeutique de matière médicale de } \\
\text { pharmacie et de toxicologie pour } 1865\end{array}$ & 1865 \\
\hline A. Cheruel & $\begin{array}{l}\text { Dictionnaire historique des Institutions moeurs et } \\
\text { coutumes de la France }\end{array}$ & $1870-1884$ \\
\hline $\begin{array}{l}\text { A. Desbarrolles y Jean } \\
\text { Hippolyte }\end{array}$ & $\begin{array}{l}\text { Les Mystères ou l'Écriture art de juger les hommes sur } \\
\text { leurs autographes }\end{array}$ & 1872 \\
\hline A. Du Breuil & Manuel d'Arboriculture des ingénieurs & 1860 \\
\hline A. Duponchel, & Traité d'Hydraulique et de la géologie agricole & 1868 \\
\hline A. F. Pouriau & Manuel de Chimiste - Agriculteur & 1866 \\
\hline A. G. Heffter & Derecho Internacional Público de Europa & 1875 \\
\hline A. G. Menocal & Report of the US & 1886 \\
\hline A. H. Kératry & Inductions morales et physiologiques & 1841 \\
\hline A. Payen & Précis de Chimie industrielle & 1859 \\
\hline A. Tibulle & Élégies de A Tibulle & 1836 \\
\hline A. W. N. Pugin & Modèles dans le style ameublement Gothique du 15 siècle & $18 ? ?$ \\
\hline Abbé Moigno & Lart des projections: 103 figures & 1872 \\
\hline Adolphe Garnier & Traité des facultés de l'âme & 1880 \\
\hline Adolphe Ricard, seud. & $\begin{array}{l}\text { L’amour les femmes et le mariage: historiettes, pensées et } \\
\text { réflexions glanée à travers champs }\end{array}$ & 1862 \\
\hline Agustín Moreto y Cabaña & Comedias escogidas & 1873 \\
\hline Aimé Barreswil y Girard & Au Dictionnaire de chimie industrielle & $1861-1864$ \\
\hline Aimé Barreswil y Girard & Dictionnaire de Chimie Industrielle & $1861-1862$ \\
\hline Al Thurot & Manuel de L'histoire ancienne & 1836 \\
\hline Albert Castel & Les Tapisseries & 1879 \\
\hline Alberto Aguilera y Velasco & Colección de Códigos europeos & $1866-1875$ \\
\hline Alejandro Manzoni & Los Novios: historia milanesa del siglo XVI & 1882 \\
\hline $\begin{array}{l}\text { Alejandro Pontes y } \\
\text { Fernández }\end{array}$ & $\begin{array}{l}\text { Errores y preocupaciones populares y explicación de } \\
\text { algunos fenómenos de la naturaleza }\end{array}$ & 1868 \\
\hline Alejo García Moreno & $\begin{array}{l}\text { Elementos de historia universal: dispuestos para que } \\
\text { puedan servir de guía a los alumnos de esta asignatura }\end{array}$ & 1882 \\
\hline Alejo García Moreno & Resumen de Historia Universal & 1883 \\
\hline Alexis, seud. & $\begin{array}{l}\text { Le sommeil magnétique expliqué par le somnambule } \\
\text { Alexis en état de lucidité }\end{array}$ & 1857 \\
\hline
\end{tabular}

\section{bibliotecas}


Bibliotecas. Vol 34, N² 2, julio-diciembre, 2016, pp. 59-93. ISSN: 1409-3049 EISSN: 1659-3286

URL: http://www.revistas.una.ac.cr/index.php/bibliotecas/index

\begin{tabular}{|c|c|c|}
\hline AUTOR & TÍTULO & $\begin{array}{l}\text { AÑO DE } \\
\text { PUBLICACIÓN }\end{array}$ \\
\hline Alfred Dantés & $\begin{array}{l}\text { Bibliographique alphabétique et méthodique des hommes } \\
\text { les plus remarquables dans les lettres, les sciences et les } \\
\text { arts chez tous les peuples, a toutes les époques }\end{array}$ & 1875 \\
\hline Alfred Dantés & Dictionnaire biographique et bibliographique & 1875 \\
\hline Alfred Smee & Mon jardin & 1876 \\
\hline Alphonse de Lamartine & OEuvres complètes & 1839 \\
\hline Alphonse de Lamartine & OEuvres complètes & 1839 \\
\hline Alphonse de Lamartine & Histoire des Girondins & $1847-1866$ \\
\hline Alphonse de Lamartine & Historia de la restauración & 1854 \\
\hline Alphonse de Lamartine & Historia de La Turquía & 1855 \\
\hline Alphonse de Lamartine & La chute d'un ange & 1861 \\
\hline Alphonse de Lamartine & OEuvres complètes: publiées inédits & $1861-1862$ \\
\hline Alphonse de Lamartine & Jocelyn: épisode Journal trouvé chez un curé de Village & 1862 \\
\hline Alphonse de Lamartine & Méditations poétiques: avec commentaires & 1862 \\
\hline Alphonse de Lamartine & Secondes harmonies poétiques et religieuses & 1862 \\
\hline Alphonse de Lamartine & $\begin{array}{l}\text { Souvenirs, impressions, pensées et paysages pendant un } \\
\text { Voyage en Orient } 1832 \text {-1833 ou notes d'un voyageur }\end{array}$ & 1862 \\
\hline Amédée Burat & Les houillères de la France en 1866 & 1867 \\
\hline Amédée M Burat & Les houillères de la France en 1866: Atlas & 1867 \\
\hline André Lefévre & Les Parcs et les Jardins & 1871 \\
\hline André Lefévre & Les merveilles de Larchitecture & 1880 \\
\hline Andrés Borrego & $\begin{array}{l}\text { Visita a los principales establecimientos penales de } \\
\text { Europa, ejecutada de orden del Gobierno, seguida de la } \\
\text { exposición de un sistema aplicable a la reforma de las } \\
\text { cárceles y presidios de España }\end{array}$ & 1873 \\
\hline $\begin{array}{c}\text { Ángel de Saavedra, duque } \\
\text { de Rivas }\end{array}$ & $\begin{array}{l}\text { Sublevación de Nápoles capitaneada por Masianelo: con } \\
\text { sus antecedentes y consecuencias hasta el establecimiento } \\
\text { del gobierno español }\end{array}$ & 1881 \\
\hline Antonio Pirala & $\begin{array}{l}\text { Historia contemporánea anales desde } 1843 \text { hasta la } \\
\text { conclusión de la última guerra civil }\end{array}$ & $1875-1879$ \\
\hline Antonio Romero Ortiz & La literatura portuguesa en el siglo XIX: estudio literario & 1869 \\
\hline Apulée & Apulée & $1835-1838$ \\
\hline Apuleyo & La Metamorfosis o el Asno de Oro & 1880 \\
\hline Aristófanes & Comedias de Aristófanes & 1880 \\
\hline Arthur Schopenhauer & Aphorismes sur la Sagesse dans la vie & 1880 \\
\hline Arthur Schopenhauer & Essai sur le libre arbitre & 1880 \\
\hline Arthur Schopenhauer & Pensés \& fragments & 1881 \\
\hline Aug Laugel & Science et philosophie & 1863 \\
\hline B. A. Lenoir & Traité de la culture de la vigne et de la vinification & $1845 ?$ \\
\hline B. Pérez Galdós & La Fontana de Oro & 1870 \\
\hline
\end{tabular}




\begin{tabular}{|c|c|c|}
\hline AUTOR & TÍTULO & $\begin{array}{l}\text { AÑO DE } \\
\text { PUBLICACIÓN }\end{array}$ \\
\hline B. Pérez Galdós & Episodios Nacionales & $1877-1884$ \\
\hline B. Pérez Galdós & La familia de León Roch & $1881-1882$ \\
\hline Baltazar Lorenzo Gracian & Obras de Lorenzo Gracian & 1773 \\
\hline Bartolomé Gabarró y Borrás & $\begin{array}{l}\text { El syllabus y el estado o conspiración de la Iglesia contra el } \\
\text { Estado y Pueblo }\end{array}$ & 1883 \\
\hline $\begin{array}{l}\text { Benjamín Constant de } \\
\text { Rebecgue }\end{array}$ & Curso de política constitucional & 1823 \\
\hline $\begin{array}{l}\text { Benjamín Constant de } \\
\text { Rebecgue }\end{array}$ & Comentario sobre la ciencia de la legislación de Filangiere & 1825 \\
\hline Blaise Pascal & OEuvres complètes & $1880-1882$ \\
\hline Bourdaloue & $\begin{array}{l}\text { OEuvres complètes de Bourdaloue de la compagnie de } \\
\text { Jésus }\end{array}$ & 1812 \\
\hline Bussy - Rabutin & $\begin{array}{l}\text { Histoire amoureuse de Gaules: suivie de la France Galante: } \\
\text { romans satiriques du XVII siècle attribués au conte de } \\
\text { Bussy }\end{array}$ & 1868 \\
\hline C. C. Tacite & OEuvres de C C Tacite & $1838-1843$ \\
\hline C. D. A. Roeder & Estudios sobre Derecho Penal y Sistemas Penitenciarios & 1875 \\
\hline Camille Neustadt & $\begin{array}{l}\text { De l'emploi de l'eau comme moyen de transmission } \\
\text { de force dans les docks commerciaux et les arsenaux } \\
\text { maritimes }\end{array}$ & 1866 \\
\hline Carlos Francisco Salazar & Curso de aritmética razonada & 1885 \\
\hline $\begin{array}{l}\text { Carlos Massa Sanguineti y } \\
\text { José Massa Sanguineti }\end{array}$ & Instituciones de Derecho Público español & 1879 \\
\hline Carlos Merivale & Historia de los romanos bajo el imperio & 1879-1881 \\
\hline Cayo Cornelio Tácito & Los anales de Cayo Cornelio Tácito & 1879 \\
\hline César Cantú & Historia Universal & $1854-1865$ \\
\hline Ch. Ruelle & Historia de la Biblia & 1883 \\
\hline Charles Darwin & $\begin{array}{l}\text { Origen de las especies por medio de la selección natural o } \\
\text { conservación de las razas en su lucha por la existencia }\end{array}$ & 1877 \\
\hline $\begin{array}{l}\text { Charles Forbes comte de } \\
\text { Montalembert }\end{array}$ & Discours & 1860 \\
\hline $\begin{array}{l}\text { Charles Forbes comte de } \\
\text { Montalembert }\end{array}$ & $\begin{array}{l}\text { Histoire de Sainte Élizabeth de Hongrie Duchesse de } \\
\text { Thuringe }\end{array}$ & 1861 \\
\hline $\begin{array}{l}\text { Charles Forbes comte de } \\
\text { Montalembert }\end{array}$ & OEuvres polémiques et diverses & 1868 \\
\hline $\begin{array}{c}\text { Charles Forbes comte de } \\
\text { Montalembert }\end{array}$ & Mélanges d'Art et de Littérature & 1861 \\
\hline $\begin{array}{c}\text { Charles Forbes comte de } \\
\text { Montalembert }\end{array}$ & $\begin{array}{l}\text { Les moines d'occident: depuis saint Benoit Jusquà saint } \\
\text { Bernard }\end{array}$ & $1868-1873$ \\
\hline Charles François Dupuis & Abrégé de L'Origine de Tous les Cultes & 1836 \\
\hline Charles Ganilh & Diccionario analítico de economía política & 1827 \\
\hline Charles Lacretelle & Histoire de France, pendant le dix-huitième siècle & $1819-1826$ \\
\hline
\end{tabular}

\section{bibliotecas}


Bibliotecas. Vol 34, N² , julio-diciembre, 2016, pp. 59-93. ISSN: 1409-3049 EISSN: 1659-3286

URL: http://www.revistas.una.ac.cr/index.php/bibliotecas/index

\begin{tabular}{|c|c|c|}
\hline AUTOR & TÍTULO & $\begin{array}{l}\text { AÑO DE } \\
\text { PUBLICACIÓN }\end{array}$ \\
\hline Charles Lacretelle & Histoire de France pendant Les Guerres de religion & $1822-1844$ \\
\hline Charles Louis Panckoucke & Iconographie de la bibliothèque latine - française & 1835 \\
\hline Chauveau des Roches & $\begin{array}{l}\text { Des divers appareils servant à Élever leau pour alimentations, } \\
\text { irrigations, épuisements utilisations et description des } \\
\text { moteurs hydrauliques Belin et Vigreux }\end{array}$ & 1875 \\
\hline Christ-Martin Wieland & Pensées sur la liberté de philosopher en Matière de F01 & 1844 \\
\hline Cicéron & Obras completas & 1880 \\
\hline Cicéron & OEuvres complètes de Cicéron: rhétorique a Hernieuse & $1830-1839$ \\
\hline Claude Fleury & Histoire Ecclésiastique & 1840 \\
\hline Claudien & OEuvres complètes de Claudien & $1830-1833$ \\
\hline Claudio Bernard & Lecciones de fisiología general y medicina experimental & 1879 \\
\hline Claudio Gay & $\begin{array}{l}\text { Historia física y política de Chile según documentos } \\
\text { adquiridos en esta República durante doce años de } \\
\text { residencia en ella y publicada bajo los auspicios del } \\
\text { Supremo Gobierno }\end{array}$ & 1849 \\
\hline Clovis Lamarre & Lexposition de 1878: La Belgique & 1878 \\
\hline Clovis Lamarre et. Al. & Lexposition de 1878: L’Autriche-Hongrie & 1878 \\
\hline $\begin{array}{l}\text { Clovis Lamarre } \\
\text { y Adalbert Frout de } \\
\text { Fontpertuis }\end{array}$ & L'exposition de 1878: Les L'Inde Britannique & 1878 \\
\hline $\begin{array}{l}\text { Clovis Lamarre y Amédée } \\
\text { Roux }\end{array}$ & L'exposition de 1878: L'Italie & 1878 \\
\hline $\begin{array}{c}\text { Clovis Lamarre y Edgar } \\
\text { Zévort }\end{array}$ & La Suisse et l'exposition de 1878 & 1878 \\
\hline $\begin{array}{l}\text { Clovis Lamarre y Georges } \\
\text { Lamy }\end{array}$ & L'exposition de 1878: Le Portugal & 1878 \\
\hline $\begin{array}{l}\text { Clovis Lamarre y L. Louis- } \\
\text { Lamde }\end{array}$ & L'Espagne et l'exposition de 1878 & 1878 \\
\hline $\begin{array}{l}\text { Clovis Lamarre y Louis } \\
\text { Léger }\end{array}$ & L'exposition de 1878: La Russie & 1878 \\
\hline $\begin{array}{c}\text { Clovis Lamarre y Mis de } \\
\text { Queux de St Hilaire }\end{array}$ & La Grèce et l'exposition de 1878 & 1878 \\
\hline $\begin{array}{c}\text { Clovis Lamarre y Nathan } \\
\text { Berendzen }\end{array}$ & Le Danemark et l'exposition de 1878 & 1878 \\
\hline $\begin{array}{l}\text { Clovis Lamarre y René de là } \\
\text { Blanchére }\end{array}$ & Les pays - bas de l'exposition de 1878 & 1878 \\
\hline $\begin{array}{c}\text { Clovis Lamarre y René de là } \\
\text { Blanchére, }\end{array}$ & L'exposition de 1878: Les États-Unis & 1878 \\
\hline Conde de Floridablanca & Obras originales & 1867 \\
\hline Conde de Segur & Histoire Universelle ornée de gravures & 1839 \\
\hline Conde de Toreno & Historia del levantamiento, guerra y revolución de España & $1848-1872$ \\
\hline Conde Roselly de Lorgues & Historia de la vida y viajes de Cristóbal Colón & $1878-1881$ \\
\hline
\end{tabular}




\begin{tabular}{|c|c|c|}
\hline AUTOR & TÍTULO & $\begin{array}{l}\text { AÑO DE } \\
\text { PUBLICACIÓN }\end{array}$ \\
\hline Conrado Malte-Brun & $\begin{array}{l}\text { Géographie universelle ou description de toutes les } \\
\text { parties du monde sur un plan nouveau d’après les grandes } \\
\text { divisions naturelles du globe }\end{array}$ & 1841 \\
\hline Contes de Schmid & Contes de Schmid Cristobal von, 1768-1854 & $18--$ \\
\hline Cristóbal Colón & $\begin{array}{l}\text { Cristóbal Colón: cartas que escribió sobre el } \\
\text { descubrimiento de América y testamento que hizo a su } \\
\text { muerte }\end{array}$ & 1880 \\
\hline Cristóbal de Castillejo & Diálogo sobre las mujeres & 1878 \\
\hline D. Ramée & $\begin{array}{l}\text { Théologie cosmogonique de la reconstitution de l'ancienne } \\
\text { et primitive loi }\end{array}$ & 1853 \\
\hline Demetrio Duque y Merino & El argumento de Amadís de Gaula & 1881 \\
\hline Destutt de Tracy & Éléments d'idéologie & 1825 \\
\hline Destutt de Tracy & Commentaire sur L'esprit des Lois de Montesquieu & 1828 \\
\hline $\begin{array}{l}\text { Diego de Saavedra Fajardoy } \\
\text { Pedro Fernández Navarrete }\end{array}$ & Obras & 1866 \\
\hline Diego Hurtado de Mendoza & $\begin{array}{l}\text { La vida del Lazarillo de Tormes y de sus fortunas y } \\
\text { adversidades }\end{array}$ & 1882 \\
\hline $\begin{array}{l}\text { Directores de la Revista } \\
\text { General de Legislación y } \\
\text { Jurisprudencia }\end{array}$ & $\begin{array}{l}\text { Jurisprudencia Administrativa: colección completa de las } \\
\text { decisiones dictadas a consulta del Consejo Real, desde su } \\
\text { instalación en } 1846 \text { hasta su supresión en } 1854 \text { seguida de un } \\
\text { repertorio alfabético de las cuestiones y puntos de derecho que } \\
\text { en aquellas se resuelven }\end{array}$ & $1857-1864$ \\
\hline $\begin{array}{l}\text { Directores de la Revista } \\
\text { General de Legislación } \\
\text { y Jurisprudencia } \\
\text { Administrativa }\end{array}$ & $\begin{array}{l}\text { Colección completa de las decisiones y sentencias dictadas } \\
\text { a consulta del Consejo Real, del Tribunal Supremo } \\
\text { Contencioso - Administrativo y del Consejo de Estado, } \\
\text { desde su instalación del primero en } 1846 \text { hasta el día, } \\
\text { seguida de un índice cronológico clasificado y de un } \\
\text { repertorio alfabético de las cuestiones y puntos de derecho } \\
\text { que en aquellas se resuelven }\end{array}$ & $1865-1879$ \\
\hline Domingo Juarros & Compendio de la Historia de Guatemala & 1857 \\
\hline Douglas Montbel & Observations sur L'iliade D’Homére & $1829-1831$ \\
\hline Dupaix & $\begin{array}{l}\text { Antiquités mexicaines relation des trois expéditions du } \\
\text { capitaine Dupaix ordonnés en 1805, } 1806 \text { et } 1807 \text { pour la } \\
\text { recherche des antiquités du pays }\end{array}$ & 1834 \\
\hline E. D. Cope & $\begin{array}{l}\text { On the batrachian and reptilian of Costa Rica with notes } \\
\text { on the Herpetology and ichthyology of Nicaragua and } \\
\text { Peru }\end{array}$ & 1875 \\
\hline E. Geruzez & $\begin{array}{l}\text { Cours de littérature: rédigé d’après le programmé pour le } \\
\text { baccalauréat }\end{array}$ & 1848 \\
\hline E. Lesbazeilles, & Les colosses anciens et modernes & 1876 \\
\hline E. R. Bensley & Introducción a la lengua inglesa & 1876 \\
\hline Edgar Quinet & El cristianismo y la revolución francesa & 1879 \\
\hline Edmond Dégrange & $\begin{array}{l}\text { La Teneduría de los libros simplificada o nuevo método de } \\
\text { enseñanza de la teneduría de los libros en partida sencilla } \\
\text { y doble, que comprende el modo de tener los libros en } \\
\text { partida doble, por medio de un solo registro }\end{array}$ & 1847 \\
\hline
\end{tabular}


Bibliotecas. Vol 34, N² 2, julio-diciembre, 2016, pp. 59-93. ISSN: 1409-3049 EISSN: 1659-3286

URL: http://www.revistas.una.ac.cr/index.php/bibliotecas/index

\begin{tabular}{|c|c|c|}
\hline AUTOR & TÍTULO & $\begin{array}{c}\text { AÑO DE } \\
\text { PUBLICACIÓN }\end{array}$ \\
\hline Edmund Scherer & $\begin{array}{l}\text { Historia del Comercio de todas las Naciones, desde los } \\
\text { tiempos más remotos hasta nuestros días }\end{array}$ & 1874 \\
\hline Edouard Sylvin, & Jules Ferry & 1883 \\
\hline Eduardo Bonnier & $\begin{array}{l}\text { Tratado teórico práctico de las pruebas en derecho civil } \\
\text { y penal }\end{array}$ & 1869 \\
\hline Emilio Keller & $\begin{array}{l}\text { La Encíclica del } 8 \text { de Diciembre de 1864, y los Principios de } \\
\text { 1789; o la Iglesia, el Estado y la Libertad }\end{array}$ & 1868 \\
\hline Erasmo Caro & L'idée de Dieu et ses nouveaux critiques & 1864 \\
\hline Erasmo Caro & Le matérialisme et science & 1876 \\
\hline Erasmo Caro & Le pessimisme au XIX siécle & 1880 \\
\hline Ernesto Lehr & Tratado de Derecho civil germánico o alemán & 1878 \\
\hline Ernesto Renan & Los apóstoles & 1868 \\
\hline Ernesto Renan & Fragmentos filosóficos & 1877 \\
\hline Eugène Dumoulin & $\begin{array}{l}\text { Les Couleurs reproduites en photographie: historique, } \\
\text { théorie et pratique }\end{array}$ & 1876 \\
\hline Eugéne Huzar & La fin du monde par la science & 1865 \\
\hline $\begin{array}{l}\text { Eugenio Maffei y Ramón } \\
\text { Rúa Figueroa }\end{array}$ & $\begin{array}{l}\text { Apuntes para una Biblioteca española de libros, } \\
\text { folletos y artículos, impresos y manuscritos, relativos al } \\
\text { conocimiento y explotación de las riquezas minerales y a } \\
\text { las ciencias auxiliares }\end{array}$ & 1872 \\
\hline Eugenio Méndez Caballero & Elementos de gramática latina & 1881 \\
\hline Eurípides & Tragedias & 1879 \\
\hline Eusebio Blasco & Soledades & 1878 \\
\hline Eustaquio Palacios & $\begin{array}{l}\text { Elementos de literatura española que comprenden la } \\
\text { gramática, la versificación, la poética y la retórica }\end{array}$ & 1876 \\
\hline F. C. de Savigny & Sistema del Derecho Romano actual & 1879 \\
\hline F. de Schiller & Los bandidos: drama en cinco actos & 1878 \\
\hline F. García Ayuso & $\begin{array}{l}\text { Irán o del Indo al Tigris: descripción geográfica de los } \\
\text { países iranios, Afganistán, Beluchistán, Persia y Armenia }\end{array}$ & 1877 \\
\hline F. García Ayuso & $\begin{array}{l}\text { Gramática inglesa: método teórico práctico con un } \\
\text { catecismo gramatical en inglés para aprender a hablar este } \\
\text { idioma }\end{array}$ & 1880 \\
\hline F. Laurent & Études sur l'Histoire de l'Humanité & $1861-1869$ \\
\hline F. Laurent & La historia de la humanidad & $1879-1880$ \\
\hline F. Pí y Margall & Las nacionalidades & 1877 \\
\hline F. Pí y Margall & Estudios sobre la Edad Media & 1878 \\
\hline Federico Soulié & Las Cuatro épocas & 1877 \\
\hline Felipe Picatoste & El Universo en la ciencia antigua & 1881 \\
\hline Félix Pérez Martin & Curso de literatura latín & 1882 \\
\hline
\end{tabular}




\begin{tabular}{|c|c|c|}
\hline AUTOR & TÍTULO & $\begin{array}{l}\text { AÑO DE } \\
\text { PUBLICACIÓN }\end{array}$ \\
\hline Fermin Herran & Estudios críticos sobre Biografía, Historia, Literatura y Arte & 1872 \\
\hline Fernando de Rojas & La celestina, tragi-comedia de Calisto y Melibea & $1878-1882$ \\
\hline Florencio García Goyena & $\begin{array}{l}\text { Concordancias, motivos y comentarios del código civil } \\
\text { español }\end{array}$ & 1852 \\
\hline Foelix & $\begin{array}{l}\text { Tratado de Derecho Internacional Privado o conflicto de } \\
\text { las leyes de diferentes naciones en materia de Derecho } \\
\text { privado }\end{array}$ & 1861 \\
\hline $\begin{array}{l}\text { Fortuné Barthélemy de } \\
\text { Felice }\end{array}$ & Lecciones de derecho natural y gentes & 1841 \\
\hline Francisco de la Pisa Pajares & Prolegómenos del derecho & 1876 \\
\hline Francisco de Paula Mellado & Diccionario universal de historia y de geografía & $1846-1850$ \\
\hline Francisco de Paula Mellado & $\begin{array}{l}\text { Enciclopedia Moderna: Diccionario Universal de } \\
\text { literatura, ciencias, artes, agricultura, industria y comercio }\end{array}$ & $1851-1855$ \\
\hline Francisco de Paula Mellado & $\begin{array}{l}\text { Diccionario de artes y manufacturas de agricultura, de } \\
\text { minas, etc.: descripción de todos los procedimientos } \\
\text { industriales y fabriles }\end{array}$ & 1857 \\
\hline Francisco de Quevedo & Poesías escogidas & $1876-1877$ \\
\hline Francisco de Quevedo Villegas & Obras & 1877 \\
\hline Francisco de Rojas Zorrilla & Comedias escogidas & 1866 \\
\hline Francisco Feliú de la Peña & Fundamentos de un nuevo código militar & 1850 \\
\hline Francisco García Ayuso & Ensayo crítico de filología comparada & sf \\
\hline Francisco María Tubino & Gibraltar ante la historia, la diplomacia y la política & 1863 \\
\hline Francisco Pedregal Prida & Gimnástica civil y militar & 1884 \\
\hline François-Victor Fournel & $\begin{array}{l}\text { Curiosités théâtrales anciennes et modernes françaises et } \\
\text { étrangères }\end{array}$ & 1878 \\
\hline $\begin{array}{l}\text { Fray Benito Jerónimo Feijoo } \\
\text { y Montenegro }\end{array}$ & Obras escogidas & \\
\hline $\begin{array}{c}\text { Fray Gabriel Tellez el } \\
\text { Maestro Tirso de Molina }\end{array}$ & Comedias escogidas & 1866 \\
\hline Fray Luis de Granada & Obras & $1863-1884$ \\
\hline Fray Luis de León & Escritos del siglo XVI & 1872 \\
\hline Fray Luis de León & La perfecta casada & 1877 \\
\hline Frédéric Bastiat & $\begin{array}{l}\text { OEuvres complètes mises en ordre revues et annotées } \\
\text { d'après les manuscrits de l'auteur }\end{array}$ & 1819 \\
\hline Frédéric Bernard & $\begin{array}{l}\text { Les fêtes célèbres de l'antiquité du moyen âge et des temps } \\
\text { modernes }\end{array}$ & 1878 \\
\hline Frédéric Hoffstadt & $\begin{array}{l}\text { Principes de style Gothique: exposés d’après des } \\
\text { documents authentiques de Moyen-âge }\end{array}$ & 1851 \\
\hline Frederick Seebohm & De la reforma del derecho de gentes & 1870 \\
\hline G. Bontemps & $\begin{array}{l}\text { Guide du verrier, traité historique et pratique du la } \\
\text { fabrication des verres, cristaux, vitraux }\end{array}$ & 1868 \\
\hline
\end{tabular}


Bibliotecas. Vol 34, N² 2, julio-diciembre, 2016, pp. 59-93. ISSN: 1409-3049 EISSN: 1659-3286

URL: http://www.revistas.una.ac.cr/index.php/bibliotecas/index

\begin{tabular}{|c|c|c|}
\hline AUTOR & TÎTULO & $\begin{array}{l}\text { AÑO DE } \\
\text { PUBLICACIÓN }\end{array}$ \\
\hline G. Gerhardt y Chancel & Précis d'analyse chimique qualitative & 1862 \\
\hline $\begin{array}{l}\text { G. Gumersindo Vicuña } \\
\text { y Nicolás María Serrano }\end{array}$ & Tratado completo de Agricultura moderna & 1877 \\
\hline G. Huberson & Precis de microphotographie & 1879 \\
\hline G. Pelin & $\begin{array}{l}\text { Les phénomènes de la Folie: le spiritisme et le magnétisme } \\
\text { expliqué aux médecins et aux navrants }\end{array}$ & 1866 \\
\hline G. Ticknor & Historia de la literatura española & $1851-1856$ \\
\hline G.Barruel & $\begin{array}{l}\text { Traite de Chimie technique appliquée aux arts êta à } \\
\text { l'industrie a la pharmacie et a l'agriculture }\end{array}$ & $1856-1863$ \\
\hline Gabriel de Cardenas Z Cano & Ensayo cronológico para la historia general de La Florida & 1829 \\
\hline Gaspar Melchor de Jovellanos & Obras publicadas e inéditas & 1858 \\
\hline $\begin{array}{l}\text { Gaspar Melchor de } \\
\text { Jovellanos }\end{array}$ & El Delincuente honrado y varias obras & 1880 \\
\hline $\begin{array}{l}\text { Gaspar Melchor de } \\
\text { Jovellanos }\end{array}$ & Ley agraria & 1882 \\
\hline Gaspar Núñez de Arce & Obras dramáticas & 1879 \\
\hline Gayo Salustio Crispo & La conjuración de Catalina y la guerra de Jugurta & 1879 \\
\hline Gayo Suetonio Tranquilo & Suétone & $1830-1833$ \\
\hline Gerardus Johannes Mulder & $\begin{array}{l}\text { De la Bière sa composition chimique, sa fabrication son } \\
\text { emploi comme boisson }\end{array}$ & 1861 \\
\hline Giovanni Antonio Bianchi & $\begin{array}{l}\text { Conversaciones de Lauriso Tragiense, pastor árcade, sobre } \\
\text { los vicios y defectos del teatro moderno y el modo de } \\
\text { corregirlos y enmendarlos }\end{array}$ & 1798 \\
\hline $\begin{array}{l}\text { Gottfried Wilhelm Freiheer } \\
\text { Leibniz }\end{array}$ & Obras de Leibniz & 1878 \\
\hline Guillaume Tiberghien & $\begin{array}{l}\text { Ensayo teórico e histórico sobre la generación de } \\
\text { conocimientos humanos }\end{array}$ & 1875 \\
\hline Guillaume Tiberghien & Estudios sobre filosofía & 1875 \\
\hline Guillermo H. Prescott & Historia de la conquista del Perú & 1853 \\
\hline Guillermo Shakespeare & Hamlet príncipe de Dinamarca & 1882 \\
\hline Guizot & $\begin{array}{l}\text { L'histoire de France depuis les temps les plus reculés } \\
\text { jusqu’en } 1789 \text { Racontée à mes petits-enfants }\end{array}$ & 1879 \\
\hline Gumersindo de Azcárate & $\begin{array}{l}\text { Ensayo de una introducción al Estudio de la Legislación } \\
\text { comparada y programa de esta asignatura }\end{array}$ & 1874 \\
\hline Gumersindo de Azcárate & Estudios económicos y sociales & 1876 \\
\hline Gumersindo de Azcárate & El Self - Gouvernement y la monarquía doctrinaria & 1877 \\
\hline H. Maudsley & El crimen y la locura & 1880 \\
\hline Heinrich Ahrens & $\begin{array}{l}\text { Curso de psicología dado en Paris, bajo los auspicios del } \\
\text { Gobierno }\end{array}$ & 1873 \\
\hline Henri François D’Aguesseau & $\begin{array}{l}\text { De la autoridad de los poderes, o límites de la potestad } \\
\text { civil y eclesiástica }\end{array}$ & 1845 \\
\hline
\end{tabular}


Bibliotecas. Vol 34, № 2, julio-diciembre, 2016, pp. 59-93. ISSN: 1409-3049 EISSN: 1659-3286

URL: http://www.revistas.una.ac.cr/index.php/bibliotecas/index

\begin{tabular}{|c|c|c|}
\hline AUTOR & TÍTULO & $\begin{array}{l}\text { AÑO DE } \\
\text { PUBLICACIÓN }\end{array}$ \\
\hline Henri Martin & $\begin{array}{l}\text { Histoire de France: depuis les tempos les plus reculés } \\
\text { jusqu'en } 1789\end{array}$ & 1878 \\
\hline Henri Villain & Cuirs et peaux tannage corroyage \& mégisserie & 1866 \\
\hline Herbert Spencer & De la educación intelectual, moral y física & 1884 \\
\hline Herculano & $\begin{array}{l}\text { Leyendas y narraciones: arras por fuero de España, La } \\
\text { Dama del pie de Cerra }\end{array}$ & 1883 \\
\hline Hermann Lotze & Principes généraux de psychologie physiologique & 1876 \\
\hline Heródoto de Halicarnaso & Los nueve libros de la historia de Heródoto de Halicarnaso & 1878 \\
\hline Hippolyte Lucas & Curiosités de littéraires & 1855 \\
\hline Homero & Obras completas de Homero & 1827 \\
\hline Homero & La Ilíada & $1877-1878$ \\
\hline Horace & OEuvres complètes D'Horace & $1831-1832$ \\
\hline Horacio & Quintus Horatius Flaccus & 1823 \\
\hline Horacio & Las poesías de Horacio & 1841 \\
\hline Horacio & Horacio en España & 1885 \\
\hline Hubert & Esprit et matière & 1871 \\
\hline Hubert Howe Bancroft & The Works & $1883-1888$ \\
\hline Inmanuel Kant & Crítica de la razón práctica & 1876 \\
\hline Inmanuel Kant & Crítica del juicio & 1876 \\
\hline J. A. Fleury & Abrégé de L'Histoire D’Angleterre & 1872 \\
\hline J. Andriveau-Coujon & $\begin{array}{l}\text { Atlas classique et Universel de géographie ancienne et } \\
\text { moderne }\end{array}$ & 1850 \\
\hline J. B. des Vosges Henry & $\begin{array}{l}\text { Elementos de dibujo lineal: geometría y agrimensura, } \\
\text { dispuestos para todos los sistemas de enseñanza y } \\
\text { expresamente escritos para las escuelas de instrucción } \\
\text { primaria y las diferentes profesiones que necesitan dibujo }\end{array}$ & 1879 \\
\hline $\begin{array}{l}\text { J. C. L. Simonde de } \\
\text { Sismondi }\end{array}$ & Histoire des Français & $1821-1844$ \\
\hline $\begin{array}{l}\text { J. C. L. Simonde de } \\
\text { Sismondi }\end{array}$ & Histoire des Républiques italiennes du moyen âge & 1840 \\
\hline J. Girardin & Traité élémentaire d’Agriculture & 1874 \\
\hline J. J. Guillemin & Historia antigua & 1869 \\
\hline J. M. Sganzin y M. Reibell & $\begin{array}{l}\text { Programme ou résume des leçons d'un cours de } \\
\text { constructions avec des applications tirées spécialement de } \\
\text { l'art de l'ingénieur des ponts et chaussées }\end{array}$ & $1839-1841$ \\
\hline J. Milla, & Don Bonifacio: leyenda antigua & 1862 \\
\hline J. P. Charpentier & $\begin{array}{l}\text { Études morales et historiques sur la littérature romaine, } \\
\text { depuis son origine jusquà nos jours }\end{array}$ & 1829 \\
\hline J. P. Maygrier & Nouvelles démonstrations d’Accouchements & 1840 \\
\hline Jacques Benigne Bossuet & Oraciones Fúnebres & 1879 \\
\hline
\end{tabular}

\section{bibliotecas}


Bibliotecas. Vol 34, N² , julio-diciembre, 2016, pp. 59-93. ISSN: 1409-3049 EISSN: 1659-3286

URL: http://www.revistas.una.ac.cr/index.php/bibliotecas/index

\begin{tabular}{|c|c|c|}
\hline AUTOR & TÍTULO & $\begin{array}{l}\text { AÑO DE } \\
\text { PUBLICACIÓN }\end{array}$ \\
\hline Jacques Bresse & $\begin{array}{l}\text { Cours de mécanique appliquée: professé à lécole impériale } \\
\text { des ponts et chaussées }\end{array}$ & 1865 \\
\hline Jacques Crétineau-Joly & $\begin{array}{l}\text { Clemente XIV y los Jesuitas o sea la historia de la } \\
\text { destrucción de los Jesuitas }\end{array}$ & 1848 \\
\hline Jean Bautiste Capefigue & Marie Médicis & 1861 \\
\hline Jean Bautiste Capefigue & Marie-Thérèse impératrice D’Autriche Roi de Hongrie & 1863 \\
\hline Jean Bautiste Capefigue & Isabelle de Castille: grandeur et décadence de L’Espagne & 1869 \\
\hline Jean Dumont & Corps Universel Diplomatique du Droit des Gens & $1726-1731$ \\
\hline Jean Le Clerc & $\begin{array}{l}\text { Négociations secrètes touchant la paix de Munster et } \\
\text { d'Osnabrug; ou recueil général }\end{array}$ & 1725 \\
\hline Jeremías Benthan & Tratados de legislación civil y penal & 1838 \\
\hline Joaquín de Avendaño & $\begin{array}{l}\text { Manual completo de instrucción primaria elemental } \\
\text { y superior: para uso de los aspirantes a maestros y } \\
\text { especialmente de los alumnos de las escuelas normales de } \\
\text { la provincia }\end{array}$ & 1880 \\
\hline Joaquín Escriche & Diccionario razonado de legislación y jurisprudencia & $1874-1875$ \\
\hline Joaquín Francisco Pacheco & El Nuevo Código: apéndice & 1876 \\
\hline Joaquín Francisco Pacheco & El código penal: concordado y comentado & 1881 \\
\hline Joaquín Guichot & Estudios sobre la constitución de los Estados Unidos & 1869 \\
\hline Joaquín Lorenzo Villanueva & El Kempis de los literatos & 1880 \\
\hline Joaquín María López & $\begin{array}{l}\text { Lecciones de elocuencia en general, de flaquencia forense, } \\
\text { de elocuencia parlamentaria y de improvisación }\end{array}$ & 1849 \\
\hline Johann Gaspar Bluntschli & Derecho público universal & 1880 \\
\hline John Burley Waring & $\begin{array}{l}\text { Masterpieces de industrial art \& sculpture at the } \\
\text { international exhibitions, } 1862\end{array}$ & 1863 \\
\hline John Gillies & $\begin{array}{l}\text { Histoire de L'ancienne Grèce de ses colonies et de ses } \\
\text { conquêtes }\end{array}$ & 1787 \\
\hline John Lubbock & $\begin{array}{l}\text { Les origines de la civilisation: état primitif de l'Homme et } \\
\text { moeurs des sauvages modernes }\end{array}$ & 1877 \\
\hline José Antonio Conde & Historia de la dominación de los árabes en España & $1820-1821$ \\
\hline José Coroleu & $\begin{array}{l}\text { Los fueros de Cataluña José Pella y Forgas: escrita con la } \\
\text { ayuda de las colecciones legales, crónicas, documentos } \\
\text { inéditos de varios archivos y los mejores tratados } \\
\text { jurisconsultos y publicistas de Cataluña }\end{array}$ & 1878 \\
\hline José de Zorrilla & Composiciones varias & 1878 \\
\hline José Delboeuf & $\begin{array}{l}\text { La psychologie comme science naturelle son présent et } \\
\text { son avenir }\end{array}$ & 1876 \\
\hline José M. de Riudavets & $\begin{array}{l}\text { Lecciones de dibujo topográfico: estudios progresivos } \\
\text { dibujados y litografiados por el autor }\end{array}$ & 1878 \\
\hline José María Sbarbi & El refranero general español & $1874-1878$ \\
\hline José Monlau & $\begin{array}{l}\text { Nociones de fisiología e higiene con las nociones de } \\
\text { anatomía humana correspondientes }\end{array}$ & 1878 \\
\hline
\end{tabular}




\begin{tabular}{|c|c|c|}
\hline AUTOR & TÍTULO & $\begin{array}{l}\text { AÑO DE } \\
\text { PUBLICACIÓN }\end{array}$ \\
\hline José Tissot & $\begin{array}{l}\text { El derecho penal: estudiado en sus principios en sus } \\
\text { aplicaciones y legislaciones de los diversos pueblos del } \\
\text { mundo o introducción filosófica e histórica al estudio del } \\
\text { derecho penal }\end{array}$ & 1880 \\
\hline Joseph Droz & $\begin{array}{l}\text { De la philosophie morale ou des différents systèmes sur la } \\
\text { science de la vie }\end{array}$ & 1824 \\
\hline Juan Calderón & Análisis lógico y gramatical de la lengua española & 1861 \\
\hline Juan de Castellanos & Elegías de Varones ilustres de Indias & 1874 \\
\hline Juan de la Cruz & Poesías & 1878 \\
\hline Juan de Mariana & Obras & $1864-1872$ \\
\hline Juan de Mariana & $\begin{array}{l}\text { Del rey y de la institución real }=\text { De rège et régis } \\
\text { institutions: obra quemada en Paris por mano del verdugo } \\
\text { en tiempo de Enrique IV }\end{array}$ & 1880 \\
\hline Juan Félix Baehr & Historia de la literatura latina & 1879 \\
\hline Juan Landa & $\begin{array}{l}\text { Hombres y mujeres celebres de todos los tiempos y de } \\
\text { todos los países }\end{array}$ & $1876-1877$ \\
\hline Juan Manuel Ortiz y Lara & $\begin{array}{l}\text { Psicología: obra adaptada como texto para la enseñanza } \\
\text { de dicha asignatura }\end{array}$ & 1880 \\
\hline Juan Rico y Amat & $\begin{array}{l}\text { Diccionario de los políticos o verdadero sentido de las } \\
\text { voces y frases más usuales entre los mimos }\end{array}$ & 1855 \\
\hline Juan Rico y Amat & $\begin{array}{l}\text { Historia política y parlamentaria de España: desde los } \\
\text { tiempos primitivos hasta nuestros días }\end{array}$ & $1860-1861$ \\
\hline Juan Ruíz de Alarcón & Comedias & 1866 \\
\hline Juan Ruíz de Alarcón & $\begin{array}{l}\text { La verdad sospechosa, comedia en tres actos Mudarse por } \\
\text { mejorarse, comedia en tres actos }\end{array}$ & 1877 \\
\hline Jules Girard & Photomicrographie en cent tableaux pour projection & 1872 \\
\hline Julián López Catalán & $\begin{array}{l}\text { El arte de educar: curso completo de pedagogía teórico- } \\
\text { práctica, aplicada a las escuelas de párvulos, obra } \\
\text { indispensable a los maestros de esta clase, ventajosa a los } \\
\text { elementales y superiores, y útil a los padres de familia }\end{array}$ & $1864-1867$ \\
\hline Justino & Histoire Universelle de Justin extraite de Trogue Pompée & 1833 \\
\hline Juvénal & Satires de Juvénal & 1830 \\
\hline Kalidasa & Vikramorvasi: drama indio en sactas & 1874 \\
\hline Kalidasa & Sakúntala: drama indio en 7 actos & 1875 \\
\hline Karl David August Röder & $\begin{array}{l}\text { Las doctrinas fundamentales reinantes sobre el delito y } \\
\text { la pena en sus interiores contradicciones: ensayo crítico } \\
\text { preparatorio para la renovación del derecho penal }\end{array}$ & 1870 \\
\hline L. Bourdeau & Coordinación de las ciencias: plan de Ciencia Integral & 1884 \\
\hline L. F. Dubief & $\begin{array}{l}\text { Le liquoriste des dames ou l'art de préparer en quelques } \\
\text { instantes toutes sortes de liqueurs de table et des parfums } \\
\text { de toilette avec toutes les fleurs cultivées dans les jardins }\end{array}$ & 1870 \\
\hline L. F. Dubief & $\begin{array}{l}\text { Guide du féculier et de l'amidonnier suivi de la conversion } \\
\text { de la fécule \& de l'amidon accompagnée de gravures }\end{array}$ & 1882 \\
\hline
\end{tabular}


Bibliotecas. Vol 34, N² 2, julio-diciembre, 2016, pp. 59-93. ISSN: 1409-3049 EISSN: 1659-3286

URL: http://www.revistas.una.ac.cr/index.php/bibliotecas/index

\begin{tabular}{|c|c|c|}
\hline AUTOR & TÍTULO & $\begin{array}{l}\text { AÑO DE } \\
\text { PUBLICACIÓN }\end{array}$ \\
\hline L. Lamotte & $\begin{array}{l}\text { Cours méthodique de dessin linéaire et de géométrie } \\
\text { usuelle, applicable à tous les modes d'enseignement }\end{array}$ & 1861 \\
\hline L. Moock & $\begin{array}{l}\text { Traité pratique complet d'impression photographique aux } \\
\text { encres grasses et de phototypographie et photogravure }\end{array}$ & 1877 \\
\hline L. P. Ségur L’Ainé & $\begin{array}{l}\text { Politique de tous les cabinets de L'Europe pendant les } \\
\text { règnes de Louis XV er de Louis XVI }\end{array}$ & 1802 \\
\hline Laureano Figuerola & $\begin{array}{l}\text { Manual completo de enseñanza simultánea mutua y } \\
\text { mixta, o instrucciones para la fundación y dirección de las } \\
\text { escuelas primarias elementales y superiores }\end{array}$ & 1847 \\
\hline $\begin{array}{l}\text { Leandro Fernández de } \\
\text { Moratín }\end{array}$ & La comedia nueva. El sí de las niñas & 1877 \\
\hline León Droux & Les produits chimiques et la fabrication savons & 1878 \\
\hline Leonard Euler & $\begin{array}{l}\text { Lettres D'Euler: a une princesse d'Allemagne sur divers } \\
\text { sujets de physique et de philosophie }\end{array}$ & 1859 \\
\hline $\begin{array}{l}\text { Les soins de l'administration } \\
\text { des Mines }\end{array}$ & Études de gites minéraux & 1836 \\
\hline Lope de Vega & Comedias escogidas & $1859-1884$ \\
\hline Lope de Vega & Colección escogidas de obras no dramáticas & 1872 \\
\hline Lope de Vega & Fama póstuma. La discreta enamorada & 1882 \\
\hline Louis Alexander de Cessart & Description d'es travaux hydrauliques & $1806-1808$ \\
\hline Louis Alexander de Cessart & Description d'ex travaux hydrauliques: Atlas & 1808 \\
\hline Louis Fiaux & $\begin{array}{l}\text { La femme le mariage et le divorcé: étude de physiologie et } \\
\text { se sociologie }\end{array}$ & 1880 \\
\hline Louis Figuier & Les merveilles de L'Industrie & 1870 \\
\hline Louis Figuier & $\begin{array}{l}\text { Les merveilles de la science: description populaire des } \\
\text { inventions modernes }\end{array}$ & 1870 \\
\hline Louis Figuier & Lannée scientifique et industrielle & 1880 \\
\hline Louis Figuier & Histoire merveilleux dans les temps modernes & 1881 \\
\hline Louis Puissant & Traité de topographie, d'arpentage et nivellement & 1860 \\
\hline Louis Reybaud & Études sur les réformateurs ou socialistes modernes & 1849 \\
\hline Lucano & Pharsale de M A Lucain & $1835-1836$ \\
\hline Ludovic Lalanne & Curiosités Bibliographiques & 1857 \\
\hline Ludovic Lalanne & Curiosités littéraires & 1857 \\
\hline Luis Grégoire & Nueva geografía universal & $1883-1884$ \\
\hline M. D. Dalloz & $\begin{array}{l}\text { Table alphabétique: des vingt-deux années du recueil } \\
\text { périodique de jurisprudence, de législation et de doctrine } \\
1845 \text { à } 1867\end{array}$ & $1867-1868$ \\
\hline $\begin{array}{l}\text { M. D. Dalloz y M. Armand } \\
\text { Dalloz }\end{array}$ & $\begin{array}{l}\text { Répertoire méthodique alphabétique de législation de } \\
\text { doctrine et de jurisprudence: en matière de droit civil, } \\
\text { commercial, criminel, administratif, de droit des gens et } \\
\text { de droit public }\end{array}$ & $1845-1870$ \\
\hline
\end{tabular}




\begin{tabular}{|c|c|c|}
\hline AUTOR & TÎTULO & $\begin{array}{l}\text { AÑO DE } \\
\text { PUBLICACIÓN }\end{array}$ \\
\hline $\begin{array}{l}\text { M. D. Dalloz y M. Armand } \\
\text { Dalloz }\end{array}$ & $\begin{array}{l}\text { Recueil périodique et critique de jurisprudence, de législation } \\
\text { et de doctrine en matière civile, commerciale, criminelle, } \\
\text { administrative et de droit public }\end{array}$ & $1845-1875$ \\
\hline M. Maigne & $\begin{array}{l}\text { Arts et manufactures: exposition sommaire des méthodes } \\
\text { et procédés de l'industrie contemporaine }\end{array}$ & 1875 \\
\hline M. R. Radau & La photographie et ses applications scientifiques & 1878 \\
\hline M. Servant Beauvais & Manual clásico de filosofía & 1843-1845 \\
\hline Madame de Staël & De A Allemagne & 1850 \\
\hline Manuel Colmeiro & Principios de economía política & 1870 \\
\hline Manuel Colmeiro & Derecho administrativo español & $1876-1880$ \\
\hline Manuel Danvila y Collado & El contrato de arrendamiento y el juicio de desahucio & 1867 \\
\hline $\begin{array}{c}\text { Manuel de la Revilla } \\
\text { y Pedro de Alcántara García }\end{array}$ & $\begin{array}{l}\text { Principios generales de literatura e historia de la literatura } \\
\text { española }\end{array}$ & 1884 \\
\hline Manuel José Quintana & Obras completas & 1867 \\
\hline Manuel José Quintana & Obras inéditas & 1872 \\
\hline Manuel José Quintana & Siria y el Líbano & 1877 \\
\hline Manuel José Quintana & Vidas de los españoles celebres & 1879 \\
\hline Manuel Sales y Ferré & Filosofía de la muerte & 1877 \\
\hline Marcelino Menéndez Pelayo & Estudios poéticos & 1879 \\
\hline Marcelino Menéndez Pelayo & Historia de los heterodoxos españoles & $1880-1881$ \\
\hline $\begin{array}{l}\text { Marcellin Pierre Eugène } \\
\text { Berthelot }\end{array}$ & Sur la force de la poudre et des matières explosives & 1872 \\
\hline Mariano José de Larra & Artículos de costumbres y políticos & $1883-1884$ \\
\hline Martin Villar y García & Historia de la literatura latina & 1875 \\
\hline Mateo Orfila & Tratado de medicina legal & 1849 \\
\hline Matías Salleras & Gramática razonada de la lengua española & 1876 \\
\hline Max Müller & La ciencia de la religión & {$[1873]$} \\
\hline Max Müller & Ensayo sobre la historia de las religiones & 1878 \\
\hline Maxime Hélène & Les Galeries souterraines & 1879 \\
\hline Maxime Paulet & $\begin{array}{l}\text { Traité de la conservation des bois des substances } \\
\text { alimentaires et diverses matières organiques: étude } \\
\text { chimique de leur altération et des moyens de la prévenir, } \\
\text { théories émises et procédés de conservation appliqués } \\
\text { depuis les temps anciens jusquà nos jours }\end{array}$ & 1874 \\
\hline $\begin{array}{l}\text { Membres de la section } \\
\text { d'Agriculture de l'Institut de } \\
\text { France, etc. }\end{array}$ & Nouveau cours complet d'Agriculture du XIXe Siècle & 1838 \\
\hline Miguel de Cervantes Saavedra & Obras ilustradas & 1864 \\
\hline Miguel Luis Amunátegui & Don José Joaquín de Mora: apuntes bibliográficos & 1886 \\
\hline Miguel Plácido Peña & Inspiraciones & 1884 \\
\hline
\end{tabular}


Bibliotecas. Vol 34, N² 2, julio-diciembre, 2016, pp. 59-93. ISSN: 1409-3049 EISSN: 1659-3286

URL: http://www.revistas.una.ac.cr/index.php/bibliotecas/index

\begin{tabular}{|c|c|c|}
\hline AUTOR & TÍTULO & $\begin{array}{l}\text { AÑO DE } \\
\text { PUBLICACIÓN }\end{array}$ \\
\hline Modesto Lafuente & $\begin{array}{l}\text { Historia General de España: desde los tiempos más } \\
\text { remotos hasta nuestros días }\end{array}$ & $1819-1867$ \\
\hline N. A. Calkins & $\begin{array}{l}\text { Manual de enseñanza objetiva o instrucción elemental } \\
\text { para padres y maestros }\end{array}$ & 1879 \\
\hline N. C. Seringe & Flore des jardins et grandes cultures & $1845-1847$ \\
\hline N. L. Lemercier & Cours analytique de littérature générale & 1817 \\
\hline Narciso Campillo y Correa & Literatura preceptiva: retórica y poética & 1881 \\
\hline Nicolás Estébanez & Nociones de geografía universal & 1885 \\
\hline Nicolás Gogol & Tarass Boulba, narración rusa & 1880 \\
\hline $\begin{array}{l}\text { Nicolás y Leandro } \\
\text { Fernández de Moratin }\end{array}$ & Obras & 1871 \\
\hline Nicomedes-Pastor Díaz & Obras & 1866 \\
\hline Ovide & OEuvres complètes D'Ovide & $1834-1837$ \\
\hline Ovide & Les Métamorphoses & 1877 \\
\hline P.Terénce & Les comédies & $1830-1831$ \\
\hline Pasquale Fiore & $\begin{array}{l}\text { Tratado de Derecho Penal Internacional y de la } \\
\text { extradición }\end{array}$ & 1880 \\
\hline Paul Champion & La dynamite et la nitroglycérine & 1872 \\
\hline Paul Janet & Le matérialisme contemporain & 1875 \\
\hline Pedro Calderón de la Barca & Comedias & 1872 \\
\hline Pedro Calderón de la Barca & El Alcalde de Zalamea, comedia en tres actos. Entremeses & 1876 \\
\hline Pedro Calderón de la Barca & Teatro escogido & 1877 \\
\hline Pedro Calderón de la Barca & Poesías inéditas & 1881 \\
\hline Pedro Calderón de la Barca & Teatro selecto & 1881 \\
\hline Pedro Ribadeneira & Historia del cisma de Inglaterra & 1863 \\
\hline Pedro de Ribadeneira & Obras escogidas & 1868 \\
\hline Pedro José Francisco de Islan & Obras escogidas & 1876 \\
\hline Pedro Mata & $\begin{array}{l}\text { Tratado de medicina y cirugía legal: teoría y práctica, } \\
\text { seguido de un compendio de toxicología }\end{array}$ & $1874-1875$ \\
\hline Pellegrin Rossi & OEuvres complètes: traité de droit pénal & 1872 \\
\hline Pétrone & Le Satyricon & $1834-1835$ \\
\hline Phédre & Fables De Phédre & 1834 \\
\hline Pierre Flourens & Ontologie naturelle oc étude philosophique des êtres & 1864 \\
\hline Pierre Jean Georges Cabanis & $\begin{array}{l}\text { Rapports ou physique et du moral de l'homme des rapports } \\
\text { du physique et du moral par le docteur Cerise }\end{array}$ & 1843 \\
\hline Pierre Joseph Proudhon & $\begin{array}{l}\text { Idea general de la revolución en el s XIX: colección de } \\
\text { estudios acerca de la práctica revolucionaria e industrial }\end{array}$ & 1868 \\
\hline
\end{tabular}




\begin{tabular}{|c|c|c|}
\hline AUTOR & TÍTULO & $\begin{array}{l}\text { AÑO DE } \\
\text { PUBLICACIÓN }\end{array}$ \\
\hline Pierre Joseph Proudhon & $\begin{array}{l}\text { Contradicciones Políticas: teoría del movimiento } \\
\text { constitucional en el siglo XIX }\end{array}$ & 1880 \\
\hline Pierre Paul Dehérain & Cours de chimie agricole & 1873 \\
\hline Pierre Plamm & $\begin{array}{l}\text { Guide pratique du constructeur d’appareils économiques } \\
\text { de chauffage pour les combustibles solides et Gazeux } \\
\text { traitant des généra tués à gaz fixes et locomobiles d } \\
\text { l'application de la chaleur concentrée et du calorique } \\
\text { perçu aux chaudières à vapeur et aux fours de toute espèce }\end{array}$ & 1864 \\
\hline Pierre Siciliani & Prolégomènes a la psychogénie moderne & 1880 \\
\hline Plaute & Théâtre de Plaute & $1831-1838$ \\
\hline Pline & Histoire naturelle de Pline & $1829-1833$ \\
\hline Pline Le Jeune & Lettres & $1832-1833$ \\
\hline Plotin & Les Ennéades de Plotin & $1857-1861$ \\
\hline Plutarco & Las vidas paralelas de Plutarco & $1882-1883$ \\
\hline Plutarque & OEuvres de Plutarque & \\
\hline Poelitz, M & Metafísica de Kant: lecciones publicadas en alemán & 1877 \\
\hline Prentice Mulford & Nuestras fuerzas mentales primera & sf \\
\hline Properce & Elégies de Properce & 1834 \\
\hline Quinte-Curce & Histoire d'Alexandre le grand & 1834 \\
\hline Quintilien & Institution oratoire & $1829-1835$ \\
\hline R. H. de Ibarreta & La religión al alcance de todos & 1884 \\
\hline Rafael Cano & Lecciones de literatura general y española & 1877 \\
\hline Rafael Fernando Seijas & $\begin{array}{l}\text { El derecho internacional hispano-americano: público y } \\
\text { privado }\end{array}$ & 1885 \\
\hline Rafael M. de Labra & $\begin{array}{l}\text { La revolución Norte-Americana del siglo XVIII } \\
\text { Fundación de los Estados Unidos de América }\end{array}$ & 1881 \\
\hline Rafael María de Labra & $\begin{array}{l}\text { La colonización en la historia: conferencias del Ateneo } \\
\text { Científico Literario de Madrid }\end{array}$ & 1876 \\
\hline Rafael María de Labra & $\begin{array}{l}\text { Portugal y sus Códigos: Estudio de política y legislación } \\
\text { contemporáneas }\end{array}$ & 1877 \\
\hline $\begin{array}{l}\text { Raimundo de Miguel y } \\
\text { Navas }\end{array}$ & $\begin{array}{l}\text { Gramática hispano-latina, teórico-práctica: para el estudio } \\
\text { simultáneo de las lenguas latín y castellana comparados }\end{array}$ & 1885 \\
\hline Ramón de Campoamor & Poesías escogidas & 1879 \\
\hline $\begin{array}{l}\text { Ramón de Mesonero } \\
\text { Romanos }\end{array}$ & Dramáticos posteriores a Lope de Vega & $1858-1859$ \\
\hline $\begin{array}{l}\text { Ramón de Mesonero } \\
\text { Romanos }\end{array}$ & Artículos escogidos de las escenas matritenses & 1879 \\
\hline $\begin{array}{l}\text { Ramón de Mesonero } \\
\text { Romanos }\end{array}$ & Dramáticos contemporáneos a Lope de Vega: Colección & 1881 \\
\hline
\end{tabular}


Bibliotecas. Vol 34, N² 2, julio-diciembre, 2016, pp. 59-93. ISSN: 1409-3049 EISSN: 1659-3286

URL: http://www.revistas.una.ac.cr/index.php/bibliotecas/index

\begin{tabular}{|c|c|c|}
\hline AUTOR & TÍTULO & $\begin{array}{l}\text { AÑO DE } \\
\text { PUBLICACIÓN }\end{array}$ \\
\hline Remiero Pedro Dozy & $\begin{array}{l}\text { Investigaciones acerca de la historia y de la literatura de } \\
\text { España durante la Edad Media }\end{array}$ & $18 ? ?$ \\
\hline Ricardo Villaseñor & Lecciones de taquigrafía & 1878 \\
\hline Richard Cortambert & $\begin{array}{l}\text { Moeurs et caractères des peuples Asie - Amérique - } \\
\text { Océanie }\end{array}$ & 1879 \\
\hline Romain Rolland & Nicolai y el pensamiento social contemporáneo & sf \\
\hline Salluste & OEuvres de Salluste & 1838 \\
\hline Salomé Jil, seud. & $\begin{array}{l}\text { Un viaje al otro mundo, pasando por otras partes } 1871 \text { a } \\
1875\end{array}$ & 1875 \\
\hline Salomé Jil, seud. & Cuadros de costumbres guatemaltecas & 1882 \\
\hline Salomé Jil, seud. & $\begin{array}{l}\text { Corona fúnebre dedicada a la grata memoria del insigne } \\
\text { literato guatemalteco don José Milla }\end{array}$ & 1885 \\
\hline Salvador Viada y Vilaseca & Suplemento al código penal reformado de 1870 & 1881 \\
\hline Samuel Clegg & $\begin{array}{l}\text { Traité pratique de la fabrication et de la distribution du } \\
\text { Gaz d'éclairage et de chauffage: Atlas }\end{array}$ & 1860 \\
\hline Santa Teresa de Jesús & $\begin{array}{l}\text { Obras: conceptos del amor de Dios Exclamaciones Cartas } \\
\text { y Poesías }\end{array}$ & 1877 \\
\hline Santa Teresa de Jesús & Escritos de Santa Teresa & 1879 \\
\hline Santos Alfaro y Lafuente & $\begin{array}{l}\text { Jurisprudencia del consejo de estado sobre la procedencia } \\
\text { de las demandas administrativas, recopilada por materias } \\
\text { y extractada precedida de una introducción acerca de lo } \\
\text { que es y debería ser lo contencioso-administrativo }\end{array}$ & 1867 \\
\hline Sénèque & OEuvres complètes de Sénèque le philosophe & $1832-1836$ \\
\hline Sénèque & Tragédie de Sénèque & 1834 \\
\hline Silio Itálico & Les puniques & 1838 \\
\hline Spinoza & Obras filosóficas de Spinoza & 1878 \\
\hline Stace & OEuvres complètes de Stace & 1837 \\
\hline Theodor Mommsen & Historia de Roma & 1876 \\
\hline Théodule-Armand Ribot & La philosophie de Schopenhauer & 1874 \\
\hline Théodule-Armand Ribot & La filosofía de Schopenhauer: escuela pesimista & 1879 \\
\hline $\begin{array}{l}\text { Thomas Babington } \\
\text { Macaulay }\end{array}$ & Estudios históricos & 1879 \\
\hline $\begin{array}{l}\text { Thomas Babington } \\
\text { Macaulay }\end{array}$ & Estudios políticos & 1879 \\
\hline $\begin{array}{l}\text { Thomas Babington } \\
\text { Macaulay }\end{array}$ & Estudios bibliográficos & 1882 \\
\hline $\begin{array}{l}\text { Thomas Babington } \\
\text { Macaulay }\end{array}$ & Estudios literarios & 1882 \\
\hline Thomas Henri Martin & La vie future suivant la foi et suivant la raison & 1870 \\
\hline Tirso de Molina, seud. & $\begin{array}{l}\text { La Prudencia en la mujer, comedia en tres actos Los tres } \\
\text { maridos burlados, novela }\end{array}$ & 1876 \\
\hline
\end{tabular}




\begin{tabular}{|c|c|c|}
\hline AUTOR & TÍTULO & $\begin{array}{l}\text { AÑO DE } \\
\text { PUBLICACIÓN }\end{array}$ \\
\hline Torquato Tasso & La Gerusalemme liberata & 1853 \\
\hline $\begin{array}{c}\text { Toussaint-Bernard Émeric- } \\
\text { David }\end{array}$ & Vies des artistes anciens et modernes & 1853 \\
\hline $\begin{array}{l}\text { Tribunal Supremo de } \\
\text { Justicia }\end{array}$ & $\begin{array}{l}\text { Jurisprudencia Civil: colección completa de las sentencias } \\
\text { dictadas por el Tribunal Supremo de Justicia, en recurso } \\
\text { de nulidad, casación e injusticia notaria y en materia de } \\
\text { competencias desde la organización de aquellos en } 1838 \\
\text { hasta el día }\end{array}$ & $1857-1882$ \\
\hline Ubaldo Romero Quiñones & La educación moral de la mujer & 1877 \\
\hline $\begin{array}{l}\text { Urbano González Serrano } \\
\text { y Manuel de la Revilla y } \\
\text { Moreno }\end{array}$ & Elementos de ética o filosofía moral & 1874 \\
\hline Val Martial & Épigrammes & 1835 \\
\hline Valère Maxime & Faits et paroles mémorables & $1834-1835$ \\
\hline Valeriano Fernández Ferraz & Clave de la traducción griega y latina & 1863 \\
\hline Valerius Flaccus & L'aéronautique au con quête de la Toison D’or poème & 1835 \\
\hline Vicente Olivares Biec & $\begin{array}{l}\text { Tratado de forma de código del Derecho institucional } \\
\text { en sus relaciones con el civil, mercantil, penal y de } \\
\text { procedimientos }\end{array}$ & 1879 \\
\hline Víctor Balaguer & Estudios Históricos y Políticos & 1876 \\
\hline Víctor Balaguer & Obras poéticas & 1880 \\
\hline Victor Calliat & $\begin{array}{l}\text { Parallèle des maisons de Paris: construites depuis } 1830 \\
\text { jusquà nos jours dessiné et publié }\end{array}$ & $1850-1864$ \\
\hline Victor Duruy & $\begin{array}{l}\text { État du Mont Romain vers le temps de la Fondation de } \\
\text { L'Empire }\end{array}$ & 1853 \\
\hline Victor Duruy & Histoire des temps modernes: depuis 1453 jusquà 1789 & 1870 \\
\hline Victor Duruy & Histoire romaine: jusquà L'invasion des barbares & 1872 \\
\hline Víctor Hugo & Ruy Blas: drama en cinco actos & 1878 \\
\hline Víctor Hugo & Discursos & 1880 \\
\hline Víctor Hugo & Guillermo Shakespeare & 1880 \\
\hline Virgile & OEuvres complètes & $1835-1839$ \\
\hline Walter Bagehot & Origen de las Naciones & 1877 \\
\hline William H. Prescott & $\begin{array}{l}\text { Historia del reinado de los reyes Católicos: don Fernando } \\
\text { y doña Isabel }\end{array}$ & $1845-1846$ \\
\hline William Robertson & Historia del reinado del Emperador Carlos Quinto & 1821 \\
\hline William Robertson & Historia de la América & 1827 \\
\hline William Snake & $\begin{array}{l}\text { Les mondes habités révélations d'un esprit: développées } \\
\text { et expliquées }\end{array}$ & 1859 \\
\hline Xénophon & OEuvres complètes de Xénophon & 1855 \\
\hline
\end{tabular}

Fuente: Moya-López, 2015. 


\section{Cuadro 2}

\section{Libros sin Autor de la Colección de Santo Tomás en la Biblioteca Nacional}

\begin{tabular}{|c|c|}
\hline TÍTULO DE LA PUBLICACIÓN & $\begin{array}{c}\text { AÑO DE } \\
\text { PUBLICACIÓN }\end{array}$ \\
\hline Histoire des traitez de paix et autres négociations & 1725 \\
\hline Corps Universel Diplomatique du Droit des Gens & 1739 \\
\hline Supplément au Corps Universel Diplomatique du Droit des Gens & 1739 \\
\hline Code de l'humanité ou législation universelle, naturelle, civile et politique & 1778 \\
\hline Études relatives à L’Art des constructions & 1823 \\
\hline Teoría de las penas y de las recompensas & 1826 \\
\hline Conquista de Méjico & 1829 \\
\hline Bibliothèque Scientifique, Industrielle et Agricole des Art et Métiers & $1830-1873$ \\
\hline Les vies de Cornelius Nepos & 1837 \\
\hline Anales de la Universidad de Chile & 1852 \\
\hline $\begin{array}{l}\text { Reports by the juries on the subjects in the thirty classes into which the } \\
\text { exhibition was divided }\end{array}$ & 1852 \\
\hline $\begin{array}{l}\text { Gramática de la lengua castellana: con su tratado completo de puntua- } \\
\text { ción, prosodia, ortografía antigua y moderna, y el del análisis grama- } \\
\text { tical y Lojica }\end{array}$ & 1859 \\
\hline Escritores en prosa anteriores al siglo XV & 1860 \\
\hline La Biblia: Vulgata Latina & 1861 \\
\hline $\begin{array}{l}\text { Escritores del siglo XVI: San Juan de la Cruz Fray Pedro Malón de } \\
\text { Chaide Fray Hernando de Zarate }\end{array}$ & 1862 \\
\hline La ley hipotecaria & 1862 \\
\hline Historiadores primitivos de Indias & $1862-1877$ \\
\hline Historiadores de sucesos particulares & 1863 \\
\hline $\begin{array}{l}\text { Masterpieces de industrial art \& sculpture at the international exhibi- } \\
\text { tions, } 1862\end{array}$ & 1863 \\
\hline Novelistas posteriores a Cervantes & 1864 \\
\hline Poetas castellanos anteriores al siglo XV & 1864 \\
\hline Autos sacramentales desde su origen hasta finales del siglo XVII & 1865 \\
\hline $\begin{array}{l}\text { Lecciones de literatura y de moral: escogidas de entre las más selectas } \\
\text { de los clásicos franceses }\end{array}$ & 1866 \\
\hline Poemas épicos & 1866 \\
\hline Poetas líricos del siglo XVIII & $1869-1875$ \\
\hline
\end{tabular}




\begin{tabular}{|c|c|}
\hline Poesías líricas alemanas & 1870 \\
\hline $\begin{array}{l}\text { Epistolario español: colección de cartas de españoles ilustres antiguos } \\
\text { y modernos }\end{array}$ & $1870-1872$ \\
\hline $\begin{array}{l}\text { Curiosidades bibliográficas: colección escogida de las obras raras de ame- } \\
\text { nidad y erudición con apuntes bibliográficos de los diferentes autores }\end{array}$ & 1871 \\
\hline $\begin{array}{l}\text { Colección completa de las sentencias dictadas por el Tribunal Supremo } \\
\text { en los recursos de casación y competencias en materia criminal desde } \\
\text { la instalación de sus salas segunda y tercera en } 1870\end{array}$ & $1871-1879$ \\
\hline Romancero y cancionero sagrados: poesías cristianas morales y divinas & 1872 \\
\hline Poetas líricos del siglo XVI y XVII & $1872-1875$ \\
\hline Obras escogidas de filósofos & 1873 \\
\hline Orígenes de la lengua española & 1873 \\
\hline Romances moriscos novelescos & 1873 \\
\hline Libros de caballerías & 1874 \\
\hline Biblioteca de las Maravillas & 1875 \\
\hline Doctrinas religiosas del racionalismo contemporáneo & 1875 \\
\hline Romancero castellano & 1875 \\
\hline Tesoro de la poesía castellana siglo XVI & 1875 \\
\hline Tesoro de la poesía castellana siglo XVII & 1875 \\
\hline $\begin{array}{l}\text { Crónicas de los Reyes de Castilla desde don Alfonso el sabio hasta los } \\
\text { católicos don Fernando y doña Isabel }\end{array}$ & $1875-1878$ \\
\hline $\begin{array}{l}\text { Álbum literario dedicado a la memoria del rey de los ingenios } \\
\text { españoles: publícalo La Redacción de la revista literaria Cervantes }\end{array}$ & 1876 \\
\hline Tesoro de la poesía castellana siglo XIX & 1876 \\
\hline Tesoro de la poesía castellana siglo XVIII & 1876 \\
\hline $\begin{array}{l}\text { La gran conquista de ultramar que mandó escribir el rey don Alfonso } \\
\text { el Sabio }\end{array}$ & 1877 \\
\hline Lecture choisies & 1877 \\
\hline Tesoro de la poesía castellana siglo XV & 1877 \\
\hline $\begin{array}{l}\text { Études sur L'Exposition de 1878: annales et archives de l'industrie au } \\
\text { XIXe Siècle }\end{array}$ & 1878 \\
\hline $\begin{array}{l}\text { Lagatomaquía de Lope de Vega Carpio y la perromaquía de Francisco } \\
\text { Nieto de Molina }\end{array}$ & 1878 \\
\hline Código Civil de Méjico & 1879 \\
\hline Manuel de Mnémotechnie: première partie & 1879 \\
\hline Código civil de España & 1880 \\
\hline
\end{tabular}

\section{bibliotecas}




\begin{tabular}{|l|c|}
\hline Escritoras españolas contemporáneas & 1880 \\
\hline Índices generales & 1880 \\
\hline $\begin{array}{l}\text { La Confederación Perú, boliviana y Chile: tendencias y principios ma- } \\
\text { nifiestos de las naciones beligerantes }\end{array}$ & 1880 \\
\hline Les arts et les produits céramiques: la fabrication des briques et des tuiles & 1880 \\
\hline Los viajes de Marco Polo veneciano & 1880 \\
\hline Poetas americanos & 1880 \\
\hline Poetas bucólicos griegos & 1880 \\
\hline Fabulistas extranjeros & 1881 \\
\hline Romancero del Cid & 1881 \\
\hline Poesías líricas mejicanas & 1882 \\
\hline $\begin{array}{l}\text { Romancero general o colección de romances castellanos anteriores al } \\
\text { siglo XVIII }\end{array}$ & 1882 \\
\hline $\begin{array}{l}\text { Libro de literatura inglesa: colección de obras y piezas de los mejores } \\
\text { clásicos en prosa y en verso }\end{array}$ & 1883 \\
\hline $\begin{array}{l}\text { Novísima colección de piezas escogidas de los clásicos latinos para uso } \\
\text { de los jóvenes que se dirigen al estudio del latín }\end{array}$ & 1883 \\
\hline $\begin{array}{l}\text { Código de comercio: vigente en España, redacción de El Consultor de } \\
\text { los Ayuntamientos y de los Juzgados Municipales }\end{array}$ & 1884 \\
\hline $\begin{array}{l}\text { On behalf of United States executive departments at the international } \\
\text { exhibition held at Philadelphia, Pa, 1876 }\end{array}$ & 1884 \\
\hline $\begin{array}{l}\text { Anuario científico: principales descubrimientos, certámenes, discusiones, } \\
\text { etc que marcan el movimiento científico del año en España y el extranjero }\end{array}$ & 1885 \\
\hline & \\
\hline
\end{tabular}

Fuente: Moya-López, 2015

\section{Resultados}

La investigación es pionera ya que por primera vez se identificaron los libros extranjeros de la Colección de Santo Tomás preservados en la Sala de Colecciones Especiales Adolfo Blen de la Biblioteca Nacional Miguel Obregón Lizano. El estudio reveló que la Colección de Santo Tomás conservados en la Biblioteca Nacional, comprende 1335 libros extranjeros distribuidos en 535 títulos y 366 autores, afines a las disciplinas o materias que se impartían. 
La Colección registra 34 libros impresos del Siglo XVIII. Los textos más antiguos datan de 1725, como la obra Négociations secrètes touchant la paix de Munster et d'Osnabrug; ou recueil général del autor Jean Le Clerc, consta de 1060 páginas, formada por una colección de tomos con las negociones secretas de paz de 1641 a 1648 entre las regiones francesas de Munster y Osnabrug.

Otro texto del fondo antiguo de 1725 corresponde al título de Histoire des traitez de paix et autres négociations, Tomo $\mathrm{N}^{\text {o }} 2$ con 843 páginas, cuyo contenido presenta las negociaciones de paz que originaron las reclamaciones modernas y antiguas de todas las potencias de Europa.

Asimismo, en el estudio se cotejó que la mayor cantidad de documentos se imprimieron en 1878 y el último se editó en 1888; empero hay siete documentos de los que se desconoce la fecha exacta de edición o carecen totalmente de una. El libro impreso en 1888, año de la clausura de la Universidad de Santo Tomás, concierne a The Works de Hubert Howe Bancroft, cuyo Tomo No. 14 contiene la Historia de México de 1861-1887 y consta de 528 páginas.

Si bien se muestra que la cantidad de libros en español y francés es muy similar, en parte se debía que durante esa época, el francés constituía el idioma oficial entre la diplomacia; además, la Universidad de Santo Tomás ofrecía la cátedra de francés.

Vinculante a los criterios de citación bibliográfica, el Cuadro 2 refleja los libros de la Colección de Santo Tomás que no tienen un autor específico, por lo cual se transcribe el título con el año de publicación de la obra.

\section{Conclusiones}

La investigación llevó a cabo su cometido al realizar un rescate documental para la sociedad, que abarcó la recopilación y compilación de títulos de las obras de la Colección de Santo Tomás, legado de la Universidad de Santo Tomás, que se conserva en la Sala de Colecciones Especiales Adolfo Blen de la Biblioteca Nacional, la cual constituye un tesoro de riqueza documental y cultural para la historia de Costa Rica.

\section{bibliotecas}


La Colección de Santo Tomás se conserva en perfectas condiciones y con el fin de publicar el acervo bibliográfico, se elaboró un repertorio referencial digital cuyo objetivo es brindar el conocimiento a todo investigador de bibliotecología y otras áreas del saber humano y, a su vez, para que se divulgue en el portal del Sistema Nacional de Bibliotecas, ente al que está adscrita la Biblioteca Nacional Miguel Obregón Lizano.

La investigación evidenció que a pesar de que hombres emprendedores y visionarios fundaron la Universidad de Santo Tomás como primer centro académico superior del país, se enfrentó a una época de turbulencia política, que influyó en el cierre de la pionera institución universitaria de Costa Rica, dejando al país por más de medio siglo sin una entidad de Educación Superior hasta el año de 1940 que se creó la Universidad de Costa Rica.

\section{Referencias}

González-García, Y. (2006). Educación y Universidad. San José: Editorial UCR.

González-Villalobos, P. (1989). La Universidad de Santo Tomás. San José: Editorial UCR.

Molina-Jiménez, I. (1995). El que quiera divertirse. Libros y sociedad en Costa Rica (1750-1914) (Colección Nueva Historia). San José: Editorial UCR.

Molina-Jiménez, I. (2002). Una imprenta de Provincia. El Taller de los Sibaja en Alajuela, Costa Rica (1867-1969). San José: Imprenta Nacional.

Mora-Pana, G. (2015, 20 de setiembre). UCR: heredera de la Pontificia Universidad de Santo Tomás. Eco Católico, Actualidad, p. 4.

Moya-López, X. (2015). Legado de la colección de Libros extranjeros de la Universidad de Santo Tomás a la Biblioteca Nacional de Costa Rica "Miguel Obregón Lizano": Repertorio referencial. (Tesis de Maes- 
tría en Bibliotecología y Estudios de la Información). Universidad de Costa Rica, Sede Rodrigo Facio.

Solano-Brenes, C. y Zamora-Murillo, O. (2010). Acervo digital en texto completo de la obra de Anastasio Alfaro y Henry Pittier en publicaciones periódicas costarricenses: 1887-1949. (Tesis de Licenciatura en Bibliotecología y Ciencias de la Información). Universidad de Costa Rica, Sede Rodrigo Facio.

Solano-Navarro, Y. (2014). Repertorio de las Revistas publicadas en Costa Rica en el periodo de 1850 a 1899 y durante la primera mitad del Siglo XX perteneciente a la Biblioteca Nacional "Miguel Obregón Lizano". (Tesis de Maestría en Bibliotecología y Estudios de la Información). Universidad de Costa Rica, Sede Rodrigo Facio.

\section{Notas sobre las Autoras}

\footnotetext{
* Mag. Ruth González-Arrieta. Profesora del Posgrado y de la Escuela de Bibliotecología de la Universidad de Costa Rica. Correo electrónico ruth.gonzalez@ucr.ac.cr

** Mag. Xinia Moya-López. Bibliotecóloga de la Biblioteca Nacional Miguel Obregón Lizano de Costa Rica. Correo electrónico xmoya@sinabi.go.cr
} 